\title{
Convection Initiation and Growth at the Coast of South China. Part I: Effect of the Marine Boundary Layer Jet
}

\author{
Yu Du, Guixing Chen, Bin Han, Chuying Mai, AND Lanqiang Bai \\ School of Atmospheric Sciences, Sun Yat-sen University, and Key Laboratory of Tropical Atmosphere-Ocean System, \\ Ministry of Education, and Southern Marine Science and Engineering Guangdong Laboratory (Zhuhai), Zhuhai, China \\ MiNGHUA LI \\ Meteorological Bureau of Shenzhen Municipality, and Key Laboratory of Severe Weather in South China, Shenzhen, China
}

(Manuscript received 20 March 2020, in final form 19 June 2020)

\begin{abstract}
Convection initiation (CI) and the subsequent upscale convective growth (UCG) at the coast of South China in a warm-sector heavy rainfall event are shown to be closely linked to a varying marine boundary layer jet (MBLJ) over the northern South China Sea (NSCS). To elucidate the dynamic and thermodynamic roles of the MBLJ in CI and UCG, we conducted and analyzed convection-permitting numerical simulations and observations. Compared to radar observations, the simulations captured CI locations and the following southwest-northeast-oriented convection development. The nocturnal MBLJ peaks at $950 \mathrm{hPa}$ and significantly intensifies with turning from southwesterly to nearly southerly by inertial oscillation. The strengthened MBLJ promotes mesoscale ascent on its northwestern edge and terminus where enhanced convergence zones occur. Located directly downstream of the MBLJ, the coastal CI and UCG are dynamically supported by mesoscale ascent. From a thermodynamic perspective, a warm moist tongue over the NSCS is strengthened by the MBLJ-driven mesoscale ascent as well as by a high sea surface temperature. The warm moist tongue farther extends northeastward by horizontal transport and arrives at the coast where CI and UCG occur. Near the CI location, rapid development of a low-level saturated layer is mainly attributed to the mesoscale ascent and low-level moistening associated with the MBLJ. In addition, subsequent CI happens on either side of the original CI along the coast due to the delay of low-level moistening, which partly contributes to linear convective growth. Furthermore, ensemble simulations confirmed that a stronger MBLJ is more favorable to CI and UCG near the coast.
\end{abstract}

\section{Introduction}

Convection initiation (CI) and subsequent upscale convective growth (UCG) are major forecast challenges, especially during the night (Weckwerth and Parsons 2006; Weckwerth et al. 2019; Trier 2003). CI and UCG can occur both near and away from surface boundaries. CI and UCG near the surface boundaries are often influenced and modulated by fronts (Trier and Parsons 1993; Moore et al. 2003; Trier et al. 2020), cold pools (Rotunno et al. 1988; Schumacher and Johnson 2005; Keene and Schumacher 2013; Liu et al. 2018), and terrain effects (Wang et al. 2014; Mulholland et al. 2019). In contrast, CI and UCG away from surface boundaries often occur during the night, and their mesoscale and

\footnotetext{
Corresponding author: Yu Du, duyu7@mail.sysu.edu.cn
}

small-scale features are poorly captured by numerical models (Wilson and Roberts 2006; Davis et al. 2003). Nocturnal CI and UCG are typically associated with low-level jets (Du and Chen 2019a; Gebauer et al. 2018; Trier et al. 2017; Shapiro et al. 2018) and bores or gravity waves (Haghi et al. 2017; Parsons et al. 2019). Among these factors, low-level jets (LLJs) are regarded as an important precursor to CI and a vital supporting element to UCG (Maddox 1983; Coniglio et al. 2010, 2011).

The LLJ over the Great Plains of the United States (GPLLJ) is one of the most researched jets with regard to its characteristics (Bonner 1968; Whiteman et al. 1997), formation mechanisms (Blackadar 1957; Holton 1967), and its role in heavy rainfall including CI and UCG (Trier and Parsons 1993; Trier et al. 2017). GPLLJs develop in the boundary layer above sloping terrain and veer from southerly to southwesterly at 
night. Inertial oscillations (the Blackadar mechanism; Blackadar 1957) and thermally driven slope flows (the Holton mechanism; Holton 1967) can jointly account for the formation of GPLLJs (Du and Rotunno 2014; Shapiro et al. 2016). Previous and recent studies have proposed detailed mechanisms of GPLLJs in CI and UCG, particularly as a result of field campaigns like the International H2O Project (IHOP_2002; Weckwerth and Parsons 2006) and the Plains Elevated Convection at Night field campaign (PECAN_2015; Geerts et al. 2017). The GPLLJ can alter the dynamic and thermodynamic structure of the lower atmosphere layer assisting CI and UCG (Pitchford and London 1962; Maddox 1983; Astling et al. 1985; Trier et al. 2006; Fedorovich et al. 2017; Gebauer et al. 2018). Trier and Parsons (1993) found that nocturnal convection over the Great Plains is often initiated and develops by the strengthening low-level convergence at the northern terminus of the GPLLJ, transporting warm moist air from the south, as well as destabilizing the environment. Recent studies further reveal that the spatial and temporal heterogeneity of GPLLJs enhance convergence and updrafts at the top and eastern edge of the LLJ as a possible mechanism of CI (Fedorovich et al. 2017; Gebauer et al. 2018; Smith et al. 2019). Nocturnal GPLLJs produce gentle but persistent mesoscale vertical motions in the presence of a warm moist tongue (Shapiro et al. 2018). Such mesoscale ascent contributes to the development of moist absolutely unstable layers (MAULs) by local cooling and moistening, which promotes CI (Trier et al. 2017).

Relative to the GPLLJs, the role of LLJs in heavy rainfall in China involving the CI or UCG processes remains less clear (Luo et al. 2017; G. Chen et al. 2017; X. Chen et al. 2017; Du and Chen 2019a; Zhang and Meng 2019; Shen et al. 2020). Similar to the scenarios of the GPLLJ, the nocturnal LLJs in the southwesterly monsoon over southern China are found to trigger or maintain convection at its northern terminus by enhancing low-level convergence and transporting moisture (G. Chen et al. 2017). Zhang et al. (2019) studied elevated $\mathrm{CI}$ in a weak-lifting environment in central eastern China and found that a MAUL caused by weak lifting and moisture transport associated with a LLJ contributes to CI. Whether the spatial and temporal heterogeneity of LLJs in China play a role in CI and UCG as GPLLJs remains in need of further clarification.

Features and meteorological effects of LLJs in China are more diverse as China has more complicated topography and active synoptic forcing (e.g., monsoon flow and mei-yu front) than that of the United States. Two types of LLJs in China have been identified ( $\mathrm{Du}$ et al. 2012, 2014): (i) a boundary layer jet (BLJ) that occurs below $1 \mathrm{~km}$ and manifests as a distinct diurnal cycle with a nocturnal maximum, which is similar to the GPLLJ in formation mechanisms (e.g., Blackadar mechanism and Holton mechanism; Du et al. 2015); and (ii) synoptic-weather-related LLJ (SLLJ) that occurs at higher levels than the BLJ and is always associated with synoptic or subsynoptic forcings. BLJs are often observed over or next to high terrain and coastal areas, whereas SLLJs are always accompanied by the mei-yu front (a stationary front with strong moisture and temperature gradient in the monsoon season) over southern China. Owing to various LLJs in South China interacting with terrain, the relation between the LLJs and heavy rainfall in South China and relevant processes remain a challenging question. Through statistical study, Du and Chen (2019b) documented that marine BLJ (MBLJ) over the northern South China Sea (NSCS) and SLLJ inland of South China coast exhibit varying characteristics and regulate rainfall distribution distinctly. Du and Chen (2018) studied a heavy rainfall event in South China and found that the SLLJ and the MBLJ are more closely linked to the inland frontal heavy rainfall and coastal warm-sector heavy rainfall, respectively. The coupling of the MBLJ and SLLJ (double LLJs) facilitates CI near the coast by low-level convergence at the terminus of the MBLJ and midlevel divergence at the entrance of SLLJ (Du and Chen 2019a; Zhang and Meng 2019; Z. Li et al. 2020).

Compared to the evolution of SLLJs associated with synoptic disturbances affecting CI and UCG in heavy rainfall (Chou et al. 1990; Chen and Yu 1988; Chen et al. 1994; Chen et al. 1998; Luo et al. 2020), their counterparts in the BLJ have been less documented, in particular for the MBLJ over the NSCS due to a lack of observations over the ocean (Luo et al. 2017). Recent studies found that the interaction of MBLJ over the NSCS with coastal terrain or terrain farther north near the south coast of China plays an important role in CI and UCG (Zhang and Meng 2019; H. Li et al. 2020). Given a lack of observations over the NSCS, high uncertainty of the MBLJ intensity and location might greatly limit the forecast skill for CI and UCG. How the evolution of the MBLJ over the NSCS influences coastal convection dynamically and thermodynamically is not well known and needs to be further studied. Understanding the role of the MBLJ provides useful predictors that could aid the coastal convection forecast in South China.

Therefore, we perform high-resolution simulations as well as use observations to examine the multiscale mechanisms of the nocturnal CI and UCG at the coast of South China in a heavy rainfall event. We have developed a present two-part study to clarify this issue. The present paper (Part I) focuses on the effect of the 


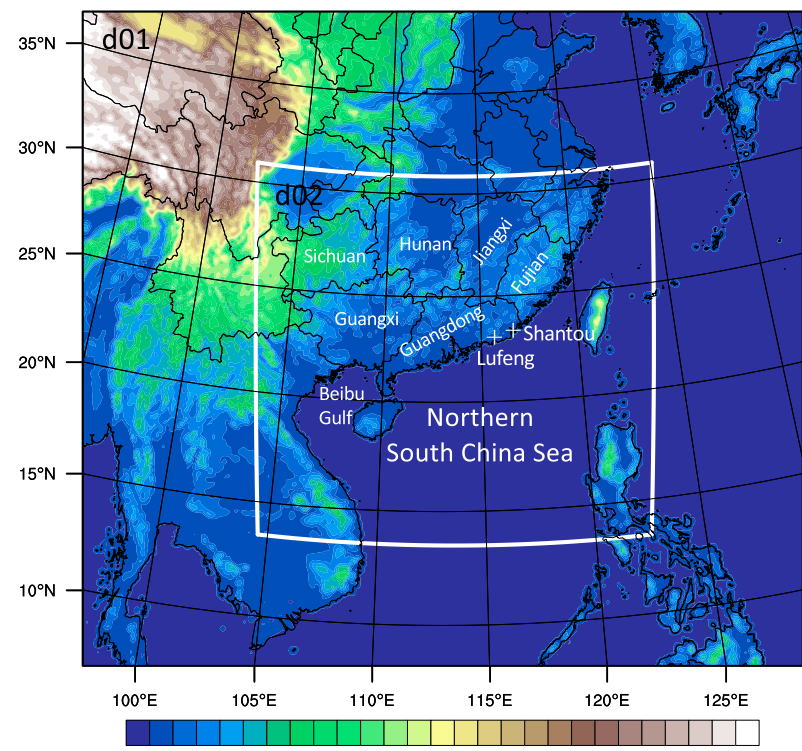

20160110011401180122012601300134013801420146015000 Terrain Height [m]

FIG. 1. Domain configurations of D01 and D02 and terrain height (shaded). White crosses indicate the locations of Shantou and Lufeng.

MBLJ over the NSCS located upstream of coastal convection, while local forcings including terrain effects and cold pools will be investigated in Part II. The observational data and numerical simulation configuration are described in section 2. In section 3 , we provide an overview of the coastal CI and UCG in a heavy rainfall case and the performance of numerical simulations thereof. Section 4 diagnoses the dynamic and thermodynamic effects of the MBLJ on CI and UCG. In section 5, ensemble simulations are further analyzed to examine the mechanisms proposed in section 4. Finally, section 6 summarizes our results.

\section{Data and methods}

\section{a. Observational data}

The Climate Prediction Center morphing technique (CMORPH) rainfall data (Joyce et al. 2004) with horizontal spatial resolution of $8 \mathrm{~km}$ and temporal resolution of $30 \mathrm{~min}$ is used to show the observed accumulated precipitation in South China (Chen et al. 2018). Mosaic radar reflectivity obtained from operational weather radars is utilized to characterize the convection morphology in the heavy rainfall event and also to evaluate the capability of numerical model simulations described later. NCEP Final (FNL) Operational Global Reanalysis data provides the synoptic background of heavy rainfall. The upper-air soundings from Shantou $\left(23.35^{\circ} \mathrm{N}, 116.66^{\circ} \mathrm{E}\right)$, Guangdong near the CI location are applied to illustrate environmental stratification

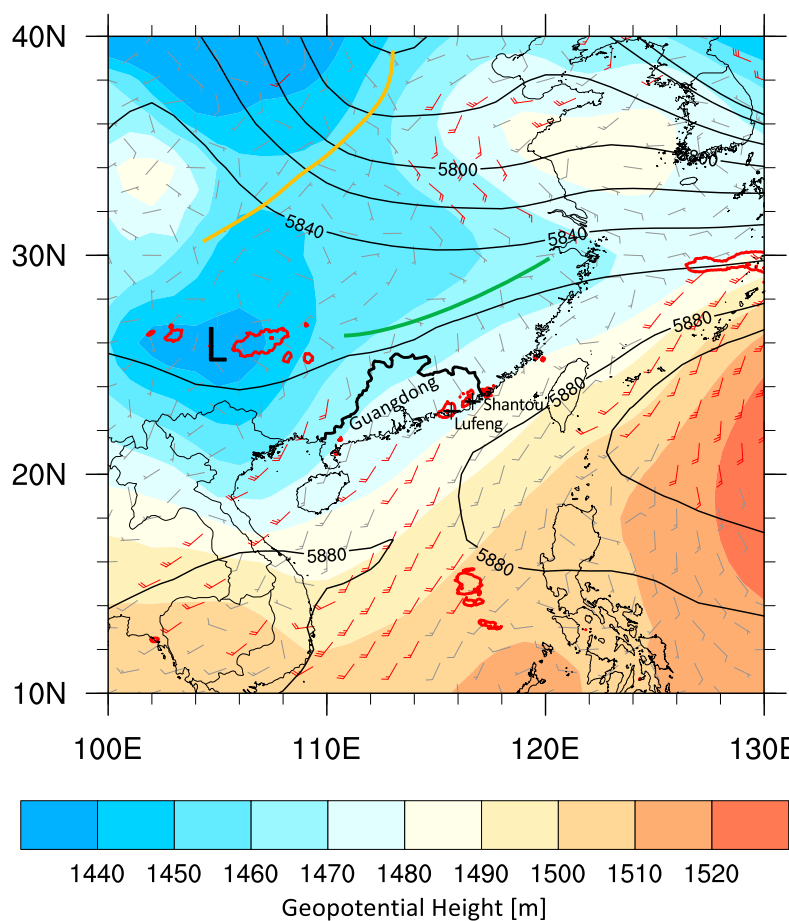

FIG. 2. Geopotential heights at $500 \mathrm{hPa}$ (black lines, contour interval $=20 \mathrm{gpm}$ ) and $850 \mathrm{hPa}$ (shaded) superimposed with horizontal wind barbs at $925 \mathrm{hPa}$ (red indicates $\geq 8 \mathrm{~ms}^{-1}$ ) at 1800 UTC 21 Jun 2018 from the NCEP FNL (Final) Operational Global Analysis data. The red contours represent the 6-h accumulated precipitation of $50 \mathrm{~mm}$ from 1800 UTC 21 Jun to 0000 UTC 22 Jun. The black "L" marks the location of a low pressure zone. The yellow line indicates a trough at $500 \mathrm{hPa}$, while the green line indicates a shear line at $925 \mathrm{hPa}$. The Guangdong province is indicated by the thick black line. The black crosses indicate the locations of Shantou and Lufeng.

structures and to compare with numerical model results as well.

\section{b. Numerical model}

The Advanced Research version of the Weather Research and Forecasting Model (WRF-ARW; version 3.9.1; Skamarock et al. 2008) was used in the present study. Figure 1 shows the domain configuration: the inner domain (d02), with a horizontal grid spacing of $4 \mathrm{~km}$, is one-way nested within an outer domain (d01) with a horizontal grid spacing of $12 \mathrm{~km}$. The model has a vertically stretched grid with 51 levels ${ }^{1}$ with finer grid spacing in the boundary layer (approximately 9 levels below $900 \mathrm{hPa}$ ). The model top is at $50 \mathrm{hPa}$

\footnotetext{
${ }^{1} \eta$ layer levels: 1.0000, 0.9974, 0.9940, 0.9905, 0.9850, 0.9800, $0.9700,0.9600,0.9450,0.9300,0.9100,0.8900,0.8650,0.8400,0.8100$, $0.7800,0.7500,0.7100,0.6800,0.6450,0.6100,0.5700,0.5300,0.4900$, $0.4500,0.4100,0.3700,0.3300,0.2900,0.2500,0.2100,0.1750,0.1450$, $0.1150,0.0900,0.0650,0.0450,0.0250,0.0100$, and 0.0000 .
} 


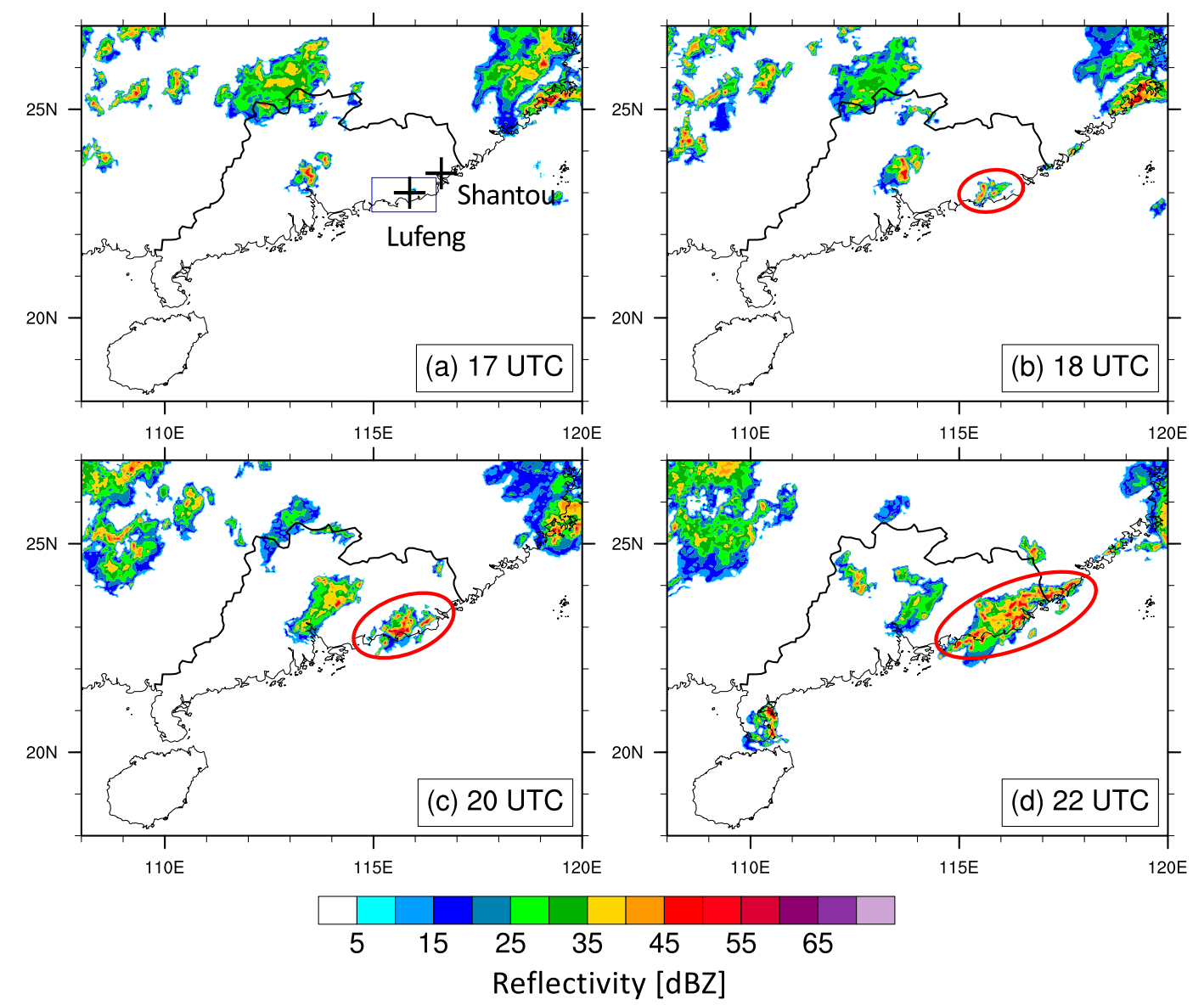

FIG. 3. Observed hourly radar composite reflectivity (shaded) from 1700 to 2200 UTC 21 Jun 2018. Red ellipses indicate the locations of convection initiation and growth. The blue box is used in Fig. 5. Local time $=\mathrm{UTC}+8 \mathrm{~h}$.

with a 5-km-deep gravity wave absorbing layer. The simulations are initialized from the 1200 UTC 21 June 2018 NCEP FNL data with lateral boundary condition updates every $6 \mathrm{~h}$. The Kain-Fritsch convection parameterization (Kain 2004) is used in d01 but turned off in d02. Both domains use the Thompson et al. (2008) bulk microphysics scheme, the YSU boundary layer scheme (Hong et al. 2006), the Rapid Radiative Transfer Model for Global Climate Models (RRTMG) longwave and shortwave radiation schemes (Iacono et al. 2008), the revised MM5 Monin-Obukhov surface-layer scheme (Jiménez et al. 2012), and the unified Noah land surface model (Livneh et al. 2011).

To examine the mechanisms of CI and UCG, this study conducted a 20-member WRF ensemble simulation initialized with the Global Ensemble Forecast System (GEFS) data (Toth and Kalnay 1993). The GEFS is a weather forecast made up of 21 separate forecasts conducted by NCEP. The GEFS is initialized by the method of Ensemble Transform with Rescaling (ETR) (Wei et al. 2008) and Stochastic Total Tendency
Perturbation (STTP). The configuration of our WRF ensemble simulations is the same as the control run above. The first member of GEFS is a deterministic forecast of GFS, while the control run is driven by FNL (i.e., the reanalysis of GFS), and thereby the WRF simulation initialized with the first member of GEFS is similar to the control run. Therefore, 20-member WRF ensemble simulation is performed, which is initialized with the 2nd to 21st members of GEFS.

\section{Convection initiation and growth in a heavy rainfall}

On 21-22 June 2018, heavy rainfall occurred both at the coast of South China and over southwestern China (Fig. 2). Figure 2 presents the synoptic conditions at 1800 UTC 21 June as well as 6-h accumulated precipitation from 1800 UTC 21 June to 0000 UTC 22 June. A deep SW-NE-oriented trough at $500 \mathrm{hPa}$ (yellow line) occurred over northern China while a low pressure vortex at $850 \mathrm{hPa}$ (labeled "L") was centered over 


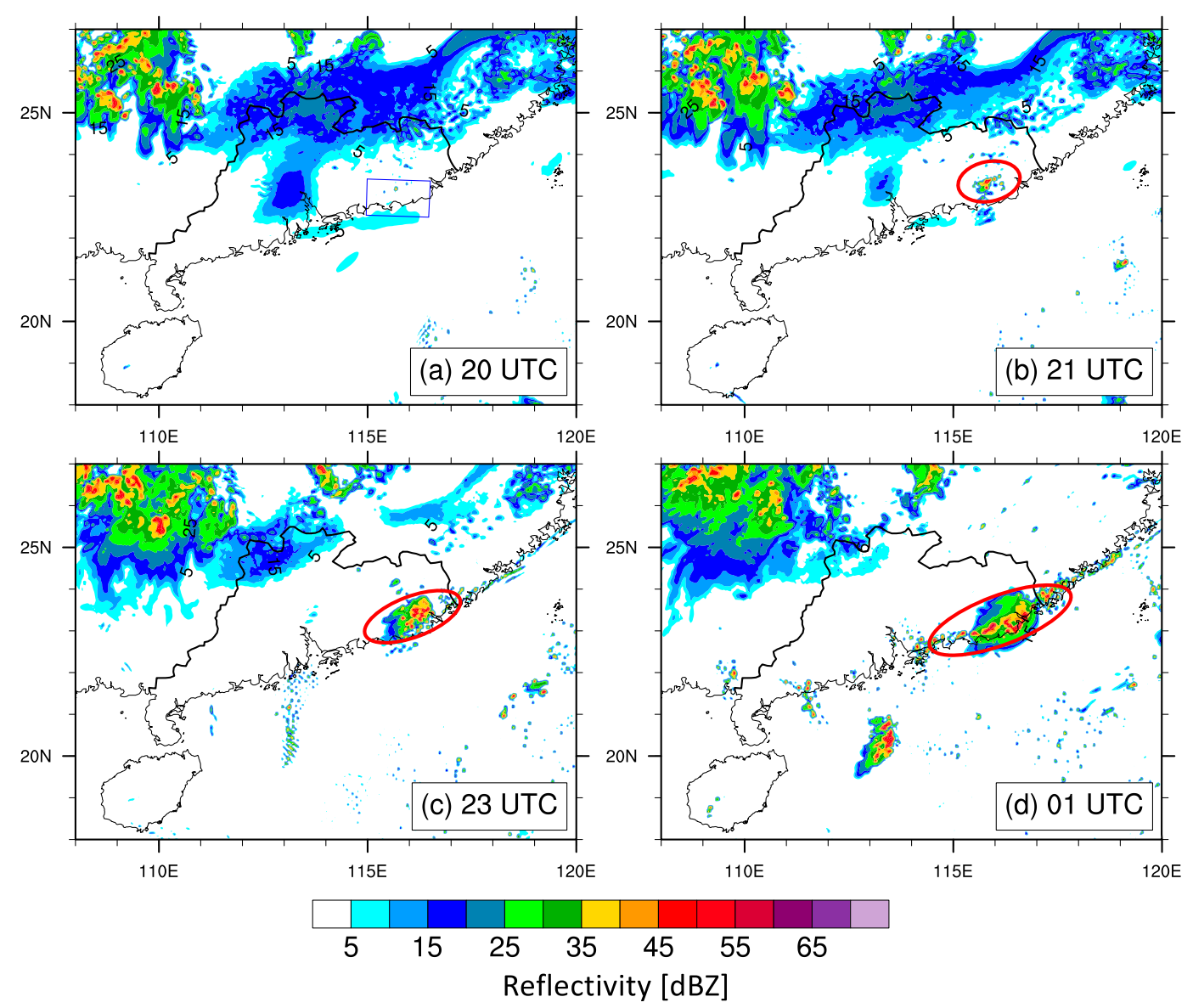

FIG. 4. Simulated hourly radar composite reflectivity (shaded) from 2000 UTC 21 Jun to 0100 UTC 22 Jun 2018. Red ellipses indicate the locations of convection initiation and growth. The blue box is used in Fig. 5. Local time $=\mathrm{UTC}+8 \mathrm{~h}$.

southwestern China $\left(26^{\circ}, 115^{\circ} \mathrm{N}\right)$. A west-east-oriented shear line at $925 \mathrm{hPa}$ (solid green line) appeared east of the low pressure vortex as well as north of Guangdong. The 6-h accumulated precipitation near the junction of Sichuan and Guangxi $\left(26^{\circ} \mathrm{N}, 117^{\circ} \mathrm{E}\right)$ was in excess of $50 \mathrm{~mm}$ and was mainly forced by the synoptic disturbance of the low pressure vortex. Meanwhile, heavy rainfall greater than $50 \mathrm{~mm}$ in $6 \mathrm{~h}$ was also observed at the east coast of Guangdong near Shantou, which is located to the northwest of the subtropical high. Given the absence of obvious synoptic forcing (far away from the front or shear line), the coastal heavy rainfall near Shantou is regarded as a type of warm-sector heavy rainfall that remains a challenge for understanding and forecasting (Luo 2017; Luo et al. 2017; Sun et al. 2019; Wu et al. 2020a,b). Located at the upstream of the heavy rainfall near Shantou, strong southerly-tosouthwesterly winds at $925 \mathrm{hPa}\left(>8 \mathrm{~m} \mathrm{~s}^{-1}\right.$, indicated by the red wind barbs) prevailed over the northern region of the South China Sea, which is identified as a MBLJ. In this study, we mainly focus on the effect of the MBLJ on the coastal CI and UCG during this heavy-rainfall event.
To illustrate CI and subsequent UCG processes in detail, the hourly evolution of the radar composite reflectivity is shown in Fig. 3. At the eastern part of the coast of Guangdong $\left(23.1^{\circ} \mathrm{N}, 115.7^{\circ} \mathrm{E}\right.$, near Lufeng, west of Shantou), CI occurred at night (1800 UTC; Fig. 3b). Herein CI is defined as the first occurrence of radar reflectivity greater than $35 \mathrm{dBZ}$ (e.g., Weckwerth and Parsons 2006). Such nocturnal CI and rainfall are typically observed at the coasts of South China (Bai et al. 2020b; Chen et al. 2018). Then the convection developed and was organized into a SW-NE-oriented mesoscale convective system (MCS) along the coast from 1800 UTC 21 June to 0000 UTC 22 June (Figs. 3c,d). This transition from isolated convection into a larger MCS is typically called UCG. In the UCG process, the linear MCS stayed in the vicinity of the coastline and its length gradually increased along the coastline.

Compared to the radar observations, the numerical simulation accurately captures the general features of CI and UCG in this event (cf. Figs. 3 and 4). In the simulation, CI occurs at a similar location to that in the 


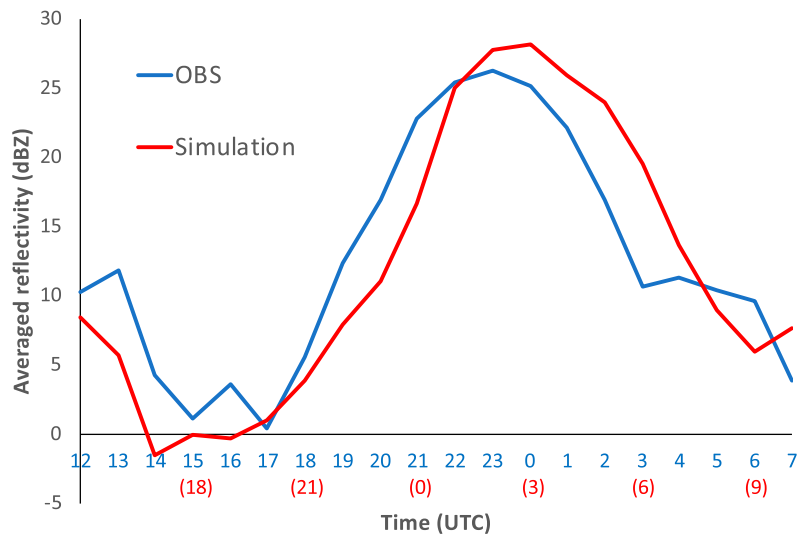

FIG. 5. Hourly evolution of averaged radar composite reflectivity within the blue boxes in Figs. 3a and 4a from the observation (blue line) and the simulation (red line). The time axis is shifted by $3 \mathrm{~h}$ for comparison between the observation (blue fonts) and the simulation (red fonts).

observations (near Lufeng) but is delayed by approximately $3 \mathrm{~h}$. The simulated convection organizes into the dominant SW-NE-oriented MCS along the coast, which is also similar to the observations (Figs. 4c,d). The comparison in the evolution of averaged reflectivity in the coastal region (blue boxes in Fig. 3a and Fig. 4a) between the observation and simulation (Fig. 5) shows their consistency in the development and decay of the coastal MCS except for 3-h delaying. It is noted that the simulation generates more moderate and stratiform-like precipitation to the north and west of the MCS compared to the observations (cf. Figs. 3 and 4). The difference might come from errors of microphysics scheme (e.g., Luo et al. 2010) or the topographic blocking of radar scans at low elevation angles by the northern terrain (Bai et al. 2020a). A possible reason for the delay of the simulated MCS is the model spin-up issue. The simulated convection tends to be initiated and developed later than the observed convection, as it takes time to generate hydrometeors in the model downscaling to finer resolutions than the initial conditions. Another reason may be the errors in the initial conditions and physics schemes that influence the timing and location of the simulated MCS. Despite the timing difference, the horizontal scale, structure, and location of CI and subsequent UCG in the numerical simulation are generally consistent with the radar observations.

We further examined the observed and simulated ambient convection environment prior to CI (1200 UTC 21 June) by comparison of upper-air soundings at the Shantou sounding station. As shown in Fig. 6, it is relatively humid through the vertical column (below $300 \mathrm{hPa}$ ) in both the observations and the simulation. The temperature profiles (lapse rate) are nearly or somewhat greater than those of the moist adiabatic. Despite of some differences, the simulation agrees with the observation in showing a rather large CAPE value (3237 vs $2462 \mathrm{~J} \mathrm{~kg}^{-1}$ ), which is favorable for convection growth in the following hours. CAPE is quite sensitive to the temperature and humidity near the surface, which can be challenging for the modeling due to complex underlying surface near the coasts. Nevertheless, the simulation can reasonably capture the general profiles of temperature and humidity.

The above evaluation suggests that the numerical simulation exhibits a fair skill in simulating the CI and (a) obs

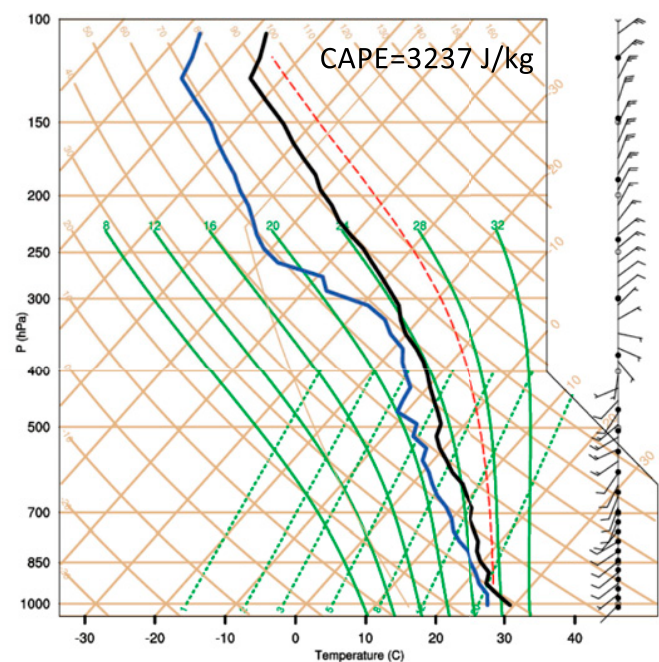

(b) WRF

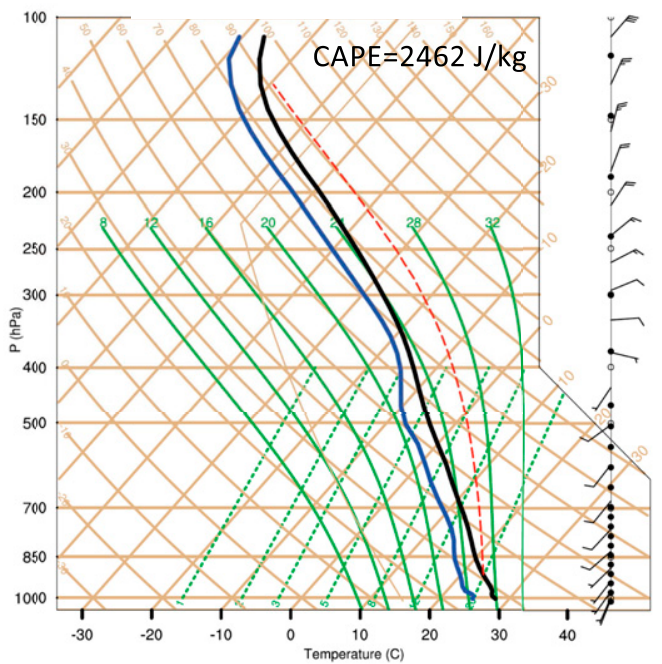

FIG. 6. Skew $T-\log p$ diagrams at the Shantou sounding station (indicated in Fig. 1) at 1200 UTC 21 Jun from (a) the observations and (b) the WRF numerical simulation. 

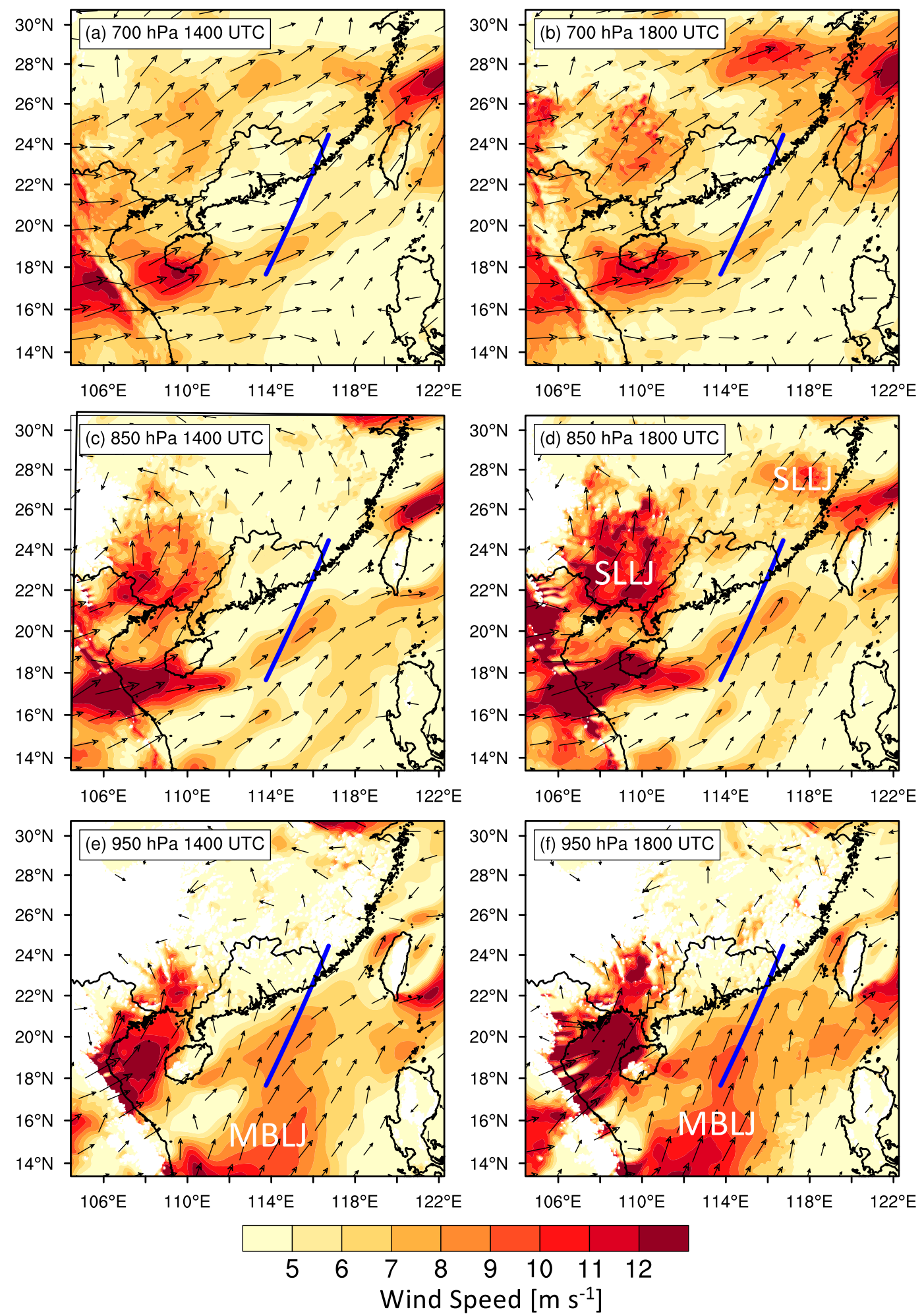

FIG. 7. Horizontal distribution of wind speed (shaded) and vectors at (a),(b) 700; (c),(d) 850; and (e),(f) $950 \mathrm{hPa}$ at (a),(c),(e) 1400 and (b),(d),(f) 1800 UTC 21 Jun 2018 from the numerical simulation. The blue lines define the cross section in Fig. 8. 

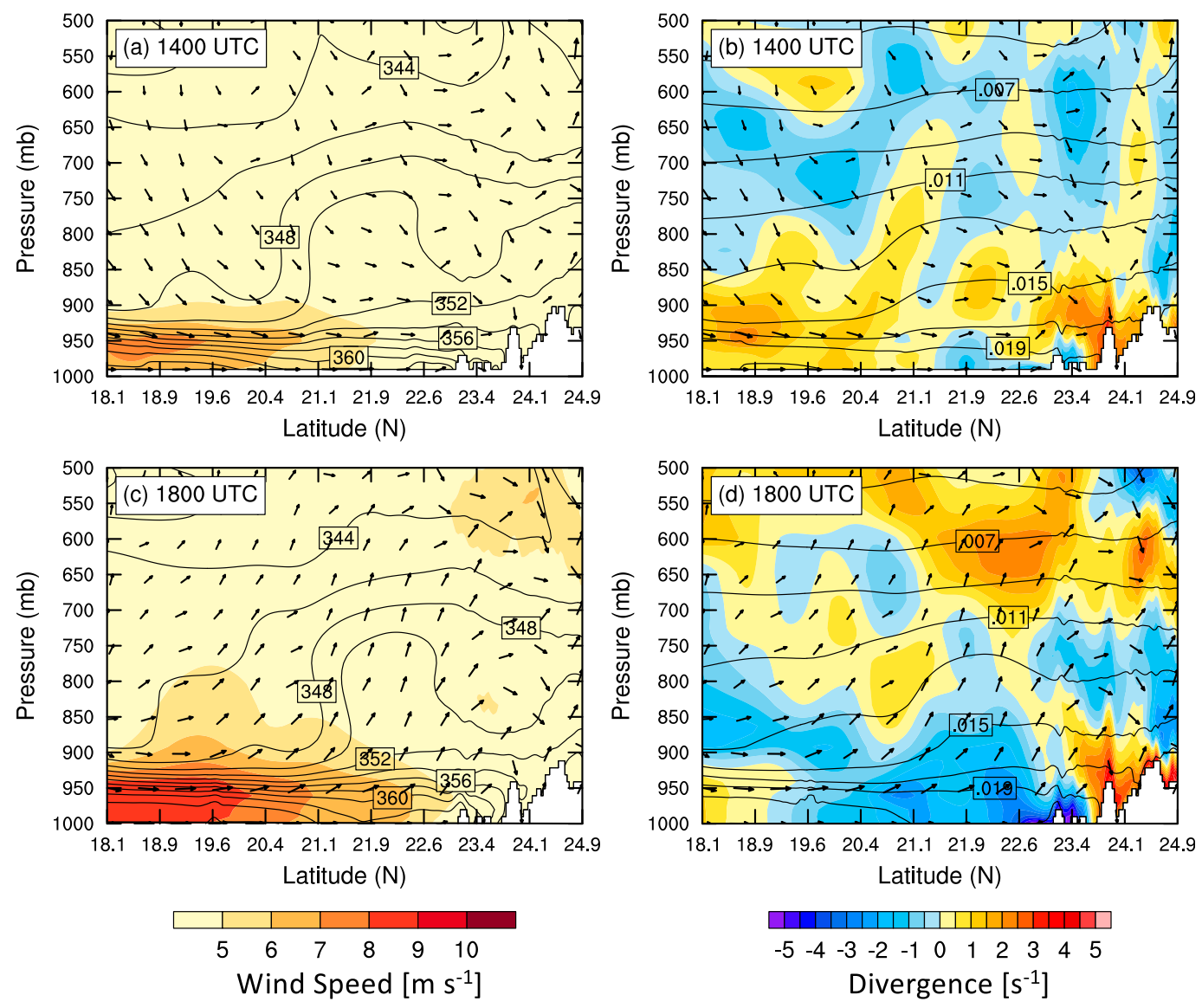

FIG. 8. Vertical cross sections along the blue line in Fig. 7 of (a),(c) wind speed (shaded), equivalent potential temperature (contours, K), and flow vectors (black vectors along the cross section and with vertical velocity amplified by 100); and (b),(d) divergence (shaded), water vapor mixing ratio (contours, $\mathrm{kg} \mathrm{kg}^{-1}$ ), and flow vectors (black vectors) at (a),(b) 1400 and (c),(d) 1800 UTC 21 Jun 2018.

UCG processes and associated atmospheric environment. Hence, it is reasonable to further explore the mechanisms of CI and UCG using the numerical simulation.

\section{Effects of MBLJ on CI and UCG}

Figure 7 shows the evolution of horizontal winds at different levels. At the 850- and 700-hPa levels (Figs. 7a-d), the strong southwesterlies over Sichuan (near $25^{\circ} \mathrm{N}, 110^{\circ} \mathrm{E}$ ) become stronger from 1400 to 1800 UTC, this strengthening is consistent with the low pressure shown in Fig. 2. Another strong southwesterly wind core (around $27^{\circ} \mathrm{N}$, $117^{\circ} \mathrm{E}$ ) is located to the south of the shear line (see Fig. 2). These two strong wind streams are, we believe, a type of SLLJ. At $950 \mathrm{hPa}$ (Figs. 7e,f), in addition to strong winds over Beibu Gulf, southerly-to-southwesterly winds over the NSCS, that are identified as the MBLJ, gradually intensify with a maximum core value of over $10 \mathrm{~m} \mathrm{~s}^{-1}$. The southwesterly MBLJ encounters the coast near Lufeng, which perhaps contributes to CI and UCG near Lufeng.
As shown in Figs. 8a and 8c, the vertical cross sections of winds and equivalent potential temperature $\theta_{e}$ along the blue line in Fig. 7 clearly show the vertical structure of the MBLJ. The MBLJ mainly occurs below $900 \mathrm{hPa}$ over the ocean with a maximum core at $\sim 950 \mathrm{hPa}$. The vertical structure of $\theta_{e}$ illustrates warm moist air is confined within the MBLJ (below $900 \mathrm{hPa}$ ). From 1400 to 1800 UTC 21 June prior to the coastal CI, the MBLJ develops and migrates to the north (right side in the Fig. 8), which induces increases in low-level convergence and mesoscale ascent near the coast (Figs. 8b,d). At 1400 UTC, low-level convergence is not evident near the coast when the MBLJ is relatively weak (Figs. 8a,b). With enhancement of the MBLJ at 1800 UTC, low-level convergence increases and therefore upward motions intensify at the exit of the MBLJ, in particular near the coast (Figs. 8c,d). Such MBLJ-driven mesoscale ascent at the exit of the MBLJ may cause CI and support subsequent UCG through upward displacements and low-level moistening. It is worthy to note that 

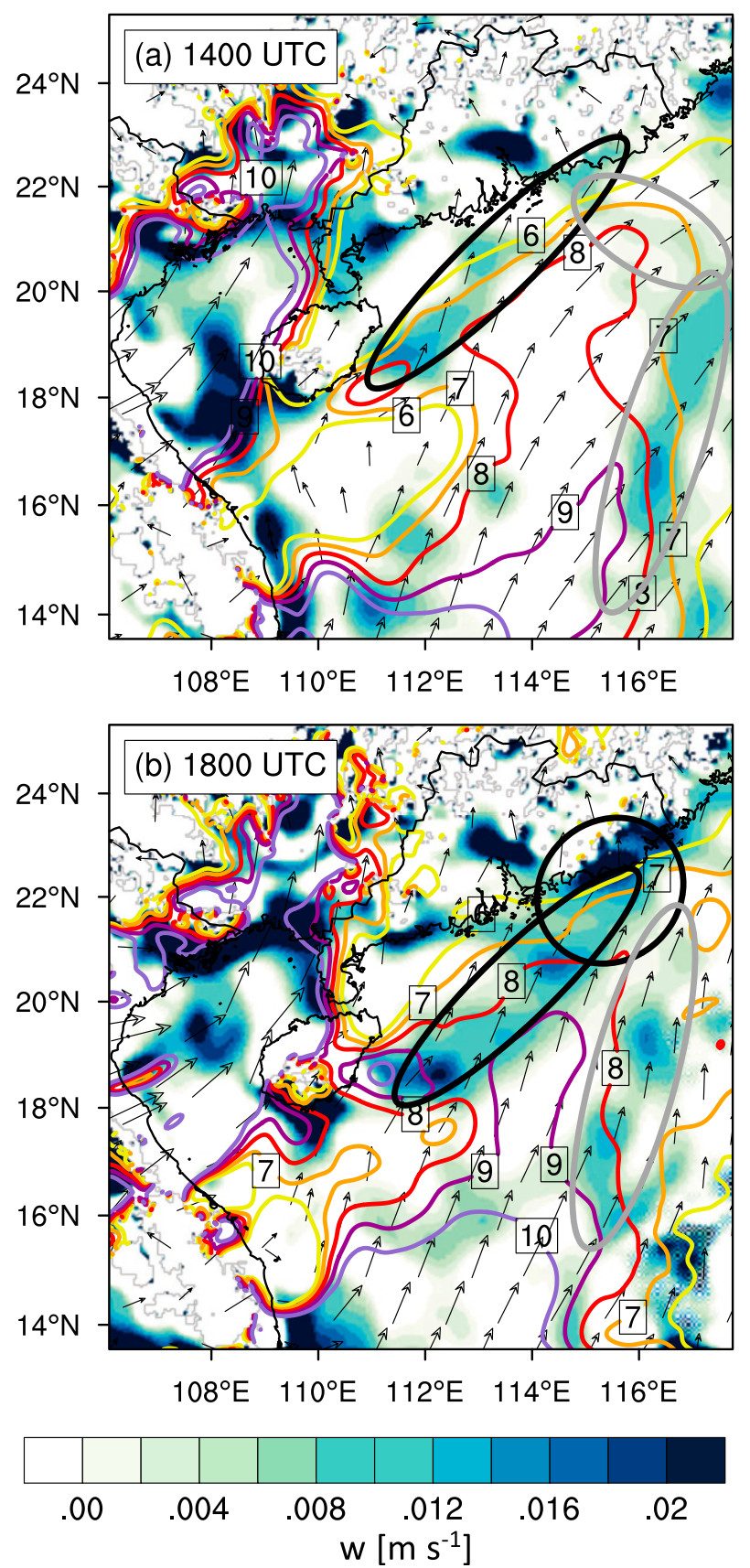

FIG. 9. Vertical motion (shaded) and horizontal wind speeds (contours $=6,7,8,9$, and $10 \mathrm{~m} \mathrm{~s}^{-1}$ ) with wind vectors at $950 \mathrm{hPa}$ at (a) 1400 and (b) 1800 UTC 21 Jun 2018.

coast-driven enhancement also plays an important role, which will be discussed in detail in Part II.

Note that the double LLJs first proposed in Du and Chen (2019a) were also found in this event. In addition to low-level (1000-900 hPa) convergence at the exit of the MBLJ, midlevel (700-500 $\mathrm{hPa})$ divergence by the entrance of SLLJ $\left(27^{\circ} \mathrm{N}, 117^{\circ} \mathrm{E}\right)$ appears near south coast of China (Figs. 7 and 8b,d). Such low-level convergence and midlevel divergence jointly promote the mesoscale lifting near the coast. The results are generally consistent with Du and Chen (2019a). In the current study, we further concentrate on the evolution of the MBLJ associated with coastal convection, on which few previous studies have focused. We will show how the MBLJ evolution affects coastal CI and subsequent UCG from the perspective of dynamics and thermodynamics in the following.

\section{a. Dynamic effect of $M B L J$}

To illustrate the relation between the horizontal structure of the MBLJ and MBLJ-driven ascent, the horizontal distribution of the horizontal winds at $950 \mathrm{hPa}$ together with vertical motions at $950 \mathrm{hPa}$ prior to $\mathrm{CI}$ are shown in Fig. 9. Figure 9 shows that low-level upward motions are significant in the region characterized by enhanced gradients of horizontal wind speed (convergence) associated with the MBLJ exit. There are three pronounced low-level mesoscale ascent zones near the northwestern and northeastern edge of the MBLJ as well as its terminus (indicated by ellipses in Fig. 9), while upward motions are not evident along the axis of the MBLJ. The nocturnal MBLJ evolution in intensity and direction can alter the location and intensity of low-level ascent zones (Fig. 9). At 1400 UTC, the relatively weak southwesterly MBLJ produces relatively weak upward motion at $950 \mathrm{hPa}$ at its northwestern edge (black ellipse) which in part affects the coast near Lufeng (Fig. 9a). At 1800 UTC prior to CI, the MBLJ intensifies in wind speed while shifting from southwesterly to nearly southerly (the westerly decreases while the southerly increases). Such development and evolution of the MBLJ is validated in ERA5 (not shown). Owing to the development of the MBLJ, low-level mesoscale ascent zones associated with the MBLJ correspondingly vary in intensity and location. Besides that the low-level mesoscale ascent in the zones is enhanced, the ascent zone at the terminus of the MBLJ moves to the coast near Lufeng with the varying direction of the MBLJ. Therefore, before CI, the enhanced mesoscale ascent (indicated by black ellipse) on the northwestern edge and terminus of the MBLJ together influence CI near Lufeng (Fig. 9b).

Next, we explain the nocturnal evolution of the MBLJ by the decomposition of geostrophic winds and ageostrophic winds. Figure 10 shows the evolution of geostrophic and ageostrophic wind vectors at $950 \mathrm{hPa}$ during 1300-1900 UTC 21 June 2018. The geostrophic winds are obtained from the smoothed geopotential height by applying a low-pass Barnes's filter $(\sim 1000 \mathrm{~km}$, Barnes 1964), while the ageostrophic winds are calculated by subtracting the geostrophic winds from filtered total wind. This filtering method has been widely applied in 


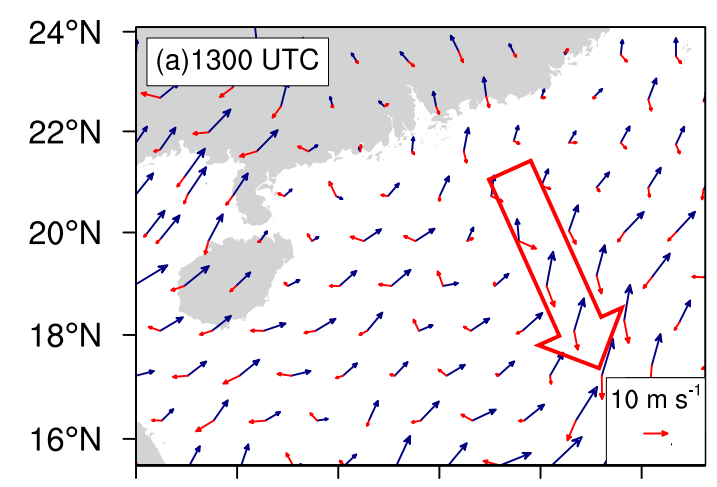

$108^{\circ} \mathrm{E} 110^{\circ} \mathrm{E} 112^{\circ} \mathrm{E} 114^{\circ} \mathrm{E} 116^{\circ} \mathrm{E} 118^{\circ} \mathrm{E}$

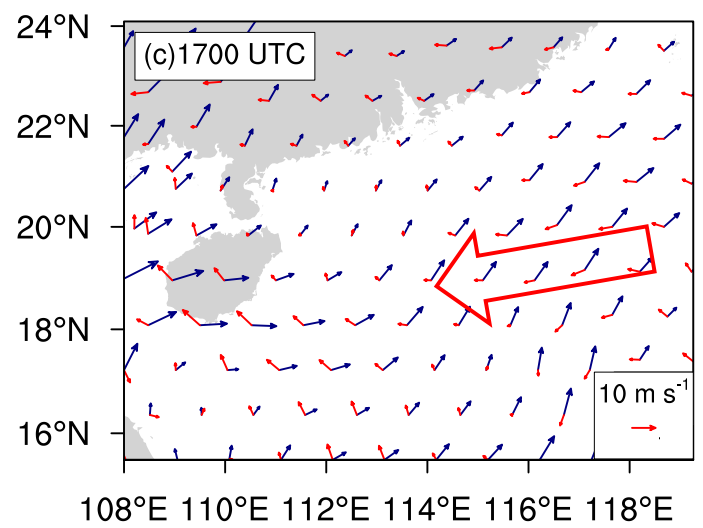

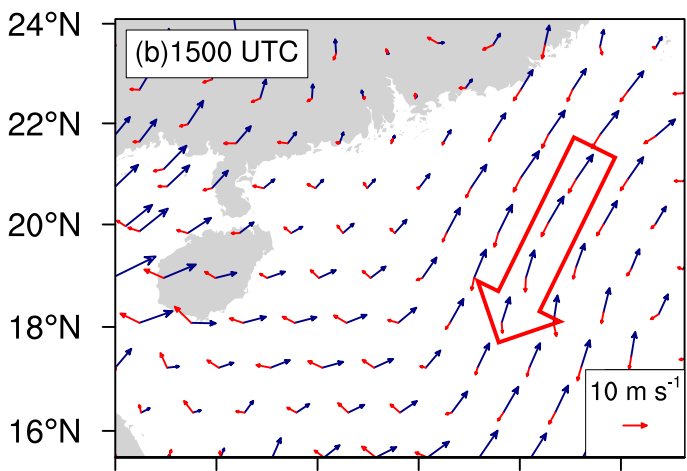

$108^{\circ} \mathrm{E} 110^{\circ} \mathrm{E} 112^{\circ} \mathrm{E} 114^{\circ} \mathrm{E} 116^{\circ} \mathrm{E} 118^{\circ} \mathrm{E}$

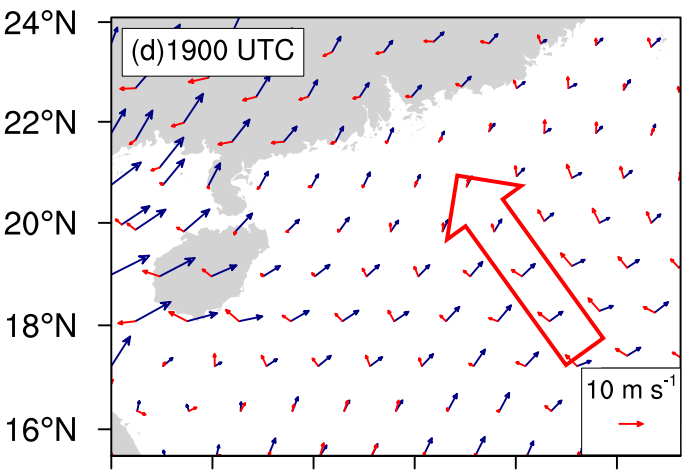

$108^{\circ} \mathrm{E} 110^{\circ} \mathrm{E} 112^{\circ} \mathrm{E} 114^{\circ} \mathrm{E} 116^{\circ} \mathrm{E} 118^{\circ} \mathrm{E}$

FIG. 10. Distribution of geostrophic winds (blue vectors) and ageostrophic winds (red vectors) at $950 \mathrm{hPa}$ from (a) 1300 to (d) 1900 UTC 21 Jun 2018. The big red arrows indicate the general direction of ageostrophic wind over that area.

previous studies of the physical mechanisms of diurnal low-level winds (Xue et al. 2018; Zeng et al. 2019). The geostrophic winds over the NSCS are southwesterly (indicated by blue vectors in Fig. 10) since it is mainly driven by the large-scale circulation (southwesterly monsoon). The southwesterly geostrophic winds even slightly decrease during the nighttime due to the weakening landsea thermal contrast, which is not consistent with the enhancing nocturnal MBLJ. By contrast, the ageostrophic winds (indicated by red vectors in Fig. 10) exhibit a clockwise rotation from northwesterly to southeasterly during the period 1300-1900 UTC, which is similar to the climatological veering of diurnal wind perturbation associated with the MBLJ (Du and Chen 2019b). Du and Chen (2019b) suggested that such diurnal wind perturbation is closely related to the large-scale (planetary-scale) landsea-breeze circulation, which has also been found in Huang et al. (2010) and Huang and Chan (2011). The ageostrophic winds veer under the Coriolis force, which is similar to the inertial oscillation mechanisms driven by the thermal contrast between land and ocean (Du et al. 2015; $\mathrm{Du}$ and Chen 2018). Therefore, the nocturnal clockwise rotation of ageostrophic winds might be attributed to the inertial oscillation associated with the large-scale seabreeze circulations, and mainly causes the variation in intensity and direction of the MBLJ at night in this event.

\section{b. Thermodynamic effect of $M B L J$}

Prior to CI, a warm moist tongue, centered at approximately $20^{\circ} \mathrm{N}, 112.5^{\circ} \mathrm{E}$ (indicated by high equivalent potential temperature at $950 \mathrm{hPa}$ in Figs. 11a-c) over the NSCS gradually enhances and extends northeastward along the northwestern edge of the MBLJ to the coast near Lufeng during 1400-2000 UTC (Figs. 11a-c). Note that the warm moist tongue is mainly characterized by a high-humidity zone through comparison of evolutions in equivalent potential temperature $\theta_{e}$ (Figs. 11a-c) and water vapor mixing ratio $q_{v}$ at $950 \mathrm{hPa}$ (Figs. 11d-f). Figure 11 shows that the moist tongue reaches the coast and thus results in water vapor saturation by low-level moistening in the layers from 1000 to $600 \mathrm{hPa}$ near the coastal region where CI occurs at 2000 UTC. Figure 12 shows that at the $\mathrm{CI}$ location the environmental lapse rate gradually increases and exceeds the moist adiabatic rate during the period 1600-2000 UTC; the CAPE correspondingly increases from 506 to $2156 \mathrm{~J} \mathrm{~kg}^{-1}$. 

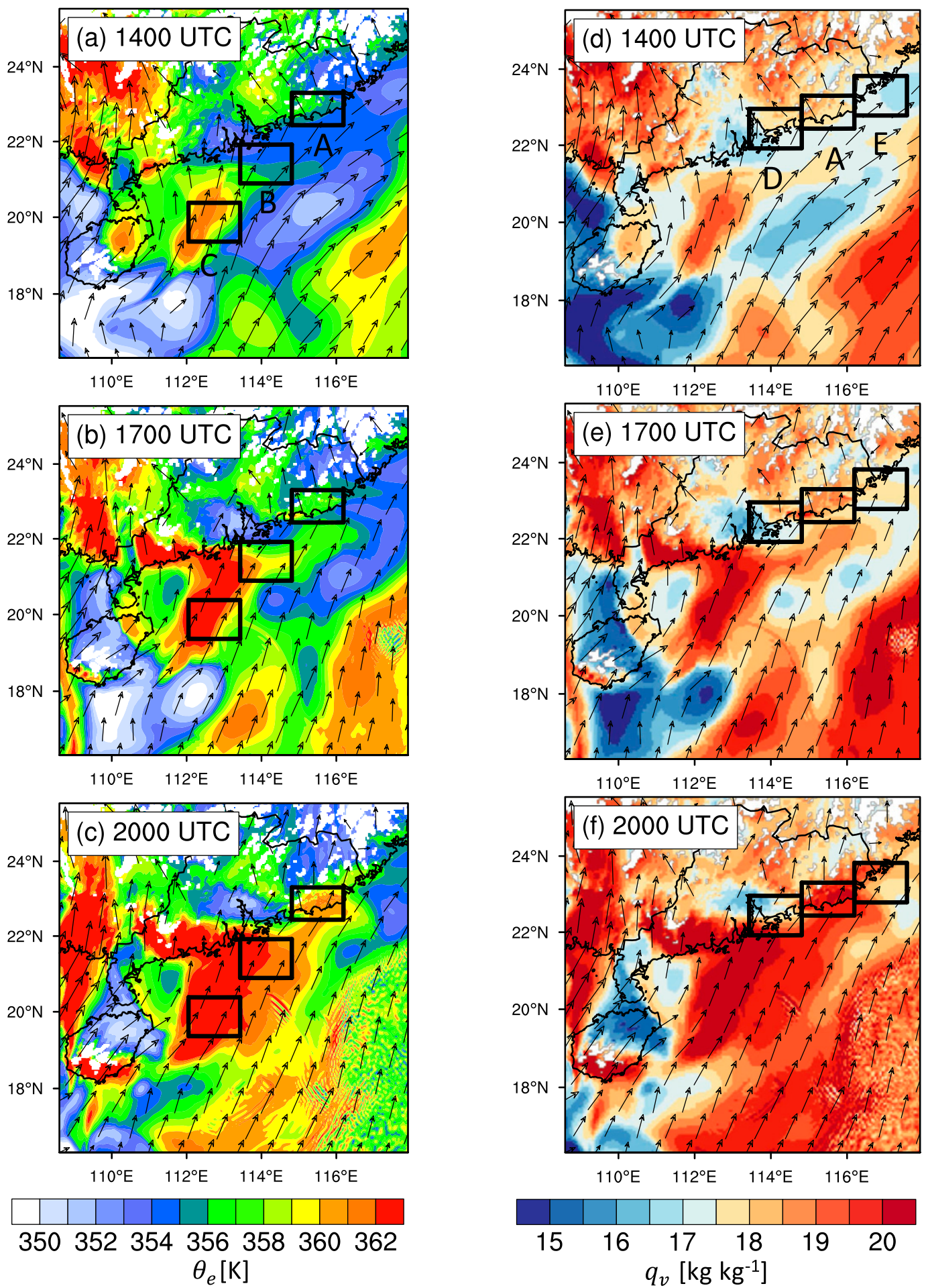

FIG. 11. Distribution of (a)-(c) equivalent potential temperature (shaded) and (d)-(f) water vapor mixing ratio (shaded) together with the horizontal wind vectors at $950 \mathrm{hPa}$ at (a),(d) 1400; (b),(e) 1700; and (c),(f) 2000 UTC 21 Jun 2018. The black boxes define regions A-E used in Fig. 13. 

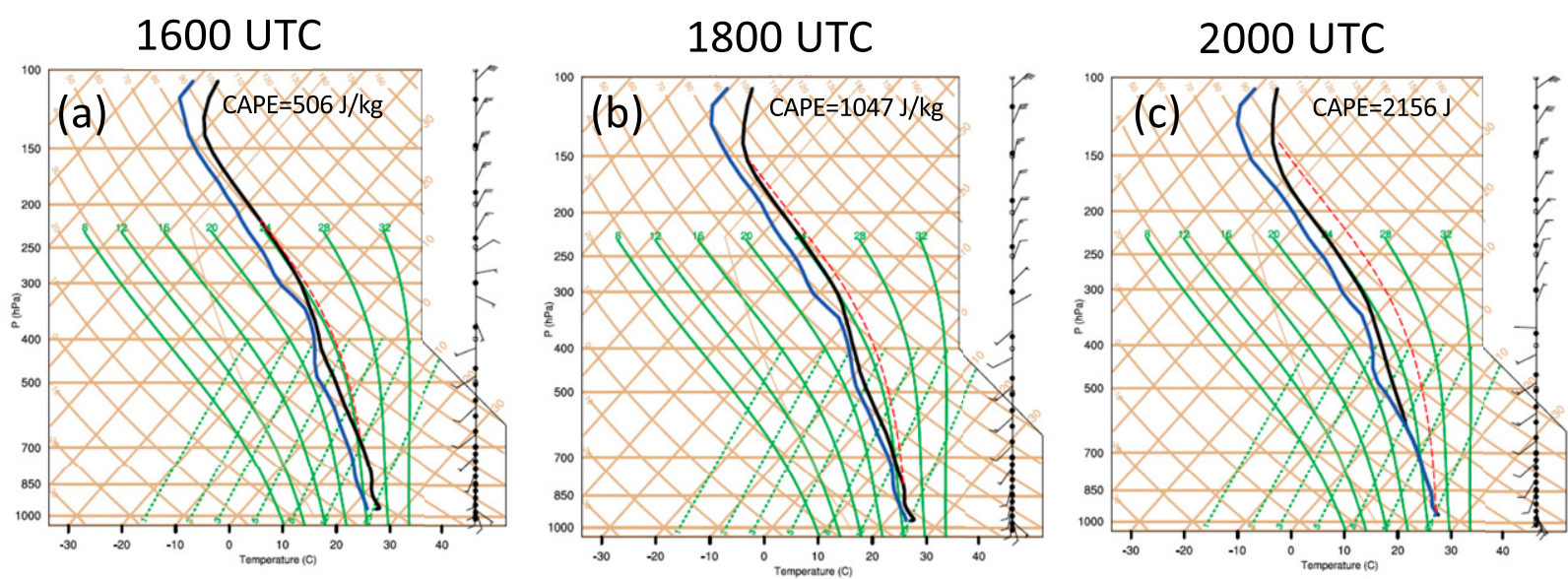

FIG. 12. Skew $T-\log p$ diagrams at the CI location $\left(23.2^{\circ} \mathrm{N}, 115.7^{\circ} \mathrm{E}\right)$ from the WRF simulation at (a) 1600 , (b) 1800 , and (c) $2000 \mathrm{UTC}$ 21 Jun 2018.

Eventually, a deep saturated layer (MAUL) within $1000-600 \mathrm{hPa}$ forms at 2000 UTC (Fig. 12c), which is associated with CI. Therefore, the low-level moistening plays an important role in supporting CI by its effect on the thermodynamics.

Next, we will elucidate the mechanisms for the lowlevel moistening. Figure 13a presents the evolution of area-averaged $q_{v}$ and relative humidity $\mathrm{RH}$ at $950 \mathrm{hPa}$ over regions A-E in Fig. 11 where convection initiates and develops during the period 1300-2300 UTC 21 June 2018. The $q_{v}(\mathrm{RH})$ increases from $0.178 \mathrm{~kg} \mathrm{~kg}^{-1}(83 \%)$ to $0.195 \mathrm{~kg} \mathrm{~kg}^{-1}$ (98\%) during the period 1300-2000 UTC prior to CI. To examine the contributions to the $q_{v}$ increase, the budget of $q_{v}$ is quantitatively diagnosed as follows:

$$
\frac{\partial q_{v}}{\partial t}=-\mathbf{V} \cdot \nabla_{h} q_{v}-w \frac{\partial q_{v}}{\partial z}+R
$$

where $\partial q_{v} / \partial t$ is the local change of $q_{v}$, while $-\mathbf{V} \cdot \nabla_{h} q_{v}$ and $-w\left(\partial q_{v} / \partial z\right)$ are horizontal and vertical transport terms, respectively, and $R$ represents the residual term. The value of $\partial q_{v} / \partial t$ is calculated by hourly centered time difference as $\left(\partial q_{v} / \partial t\right)_{t}=\left(q_{v_{t+\Delta t}}-q_{v_{t-\Delta t}}\right) / 2 \Delta t$, where $\Delta t=1 \mathrm{~h}$. It is noted that some highly transient convective signals cannot be represented in the local tendency term with such a relatively coarse time resolution. The value of $R$ is calculated from $\partial q_{v} / \partial t+\mathbf{V} \cdot \nabla_{h} q_{v}+w \partial q_{v} / \partial z$. In reality, $R$ includes the contribution from subgrid mixing (vertical turbulence mixing) in the boundary layer, condensation/evaporation effect, and computational errors (e.g., interpolation error associated with complex terrain near the coasts). In the region without cloud or convection, the contribution from the PBL should be the major portion of $R$ (Figs. 13b-f). So, we expect a small difference between these two terms as shown in Figs. 13b-f, which also suggests a reasonability for the calculation of $R$ (i.e., the computational errors are small).

Figure 13b shows all the terms at $950 \mathrm{hPa}$ in Eq. (1) averaged over region $\mathrm{A}$ and indicates that the vertical transport term is the main contributor to the local moistening, which peaks at around 1700 UTC prior to CI. The water vapor is vertically transported from lower layers containing more water vapor by the mesoscale ascent associated with the terminus of the MBLJ (Fig. 8d) while the horizontal transport term plays a minor role. Since the low-level moistening is closely related to the strengthening and expanding of the moist tongue over the ocean as mentioned previously, we further examine the evolution of water vapor and associated moisture budgets located upstream of the CI location near the moist tongue (e.g., regions B and C in Fig. 11). Similar to region A, Fig. 13a shows that $q_{v}$ also experiences increase in regions $\mathrm{B}$ and $\mathrm{C}$ (up to values $>0.02 \mathrm{~kg} \mathrm{~kg}^{-1}$ ), since regions $\mathrm{B}$ and $\mathrm{C}$ are closer to the center of the moist tongue. In contrast to region A, horizontal transport, vertical transport and the residual term contribute approximately equally to the local moistening in region $\mathrm{B}$ (Fig. 13c). Mesoscale ascent over the northwestern edge of the MBLJ induces vertical transport of water vapor, whereas moisture originated from the center of the moist tongue flows horizontally northeastward along with the MBLJ. Since region B is situated at the upstream of region $\mathrm{A}$, the horizontal transport term in region $\mathrm{B}$ reaches its peak earlier than in region A (1600 vs 1800 UTC, cf. Figs. 13b,c). The residual term also has a fair contribution to local moistening, which is mainly due to the vertical turbulence mixing in the marine boundary layer. In the center of the moist tongue (region $\mathrm{C}$ ), the vertical turbulence mixing in the marine boundary overlaying high SST becomes dominant for the enhancement of moisture 
(a)

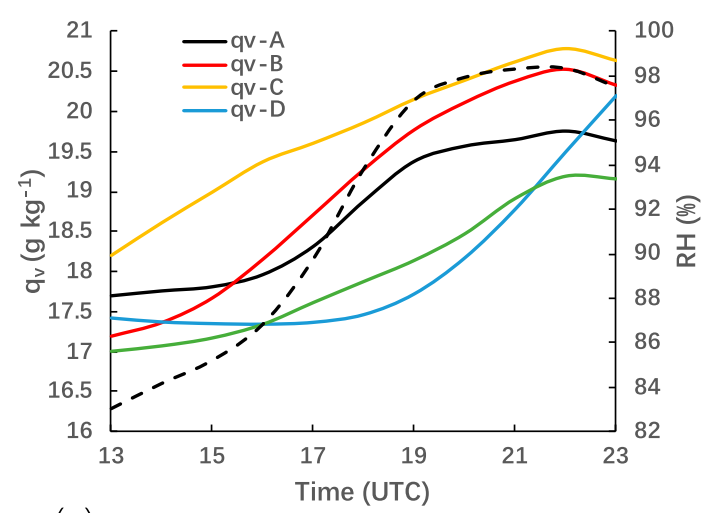

(c)

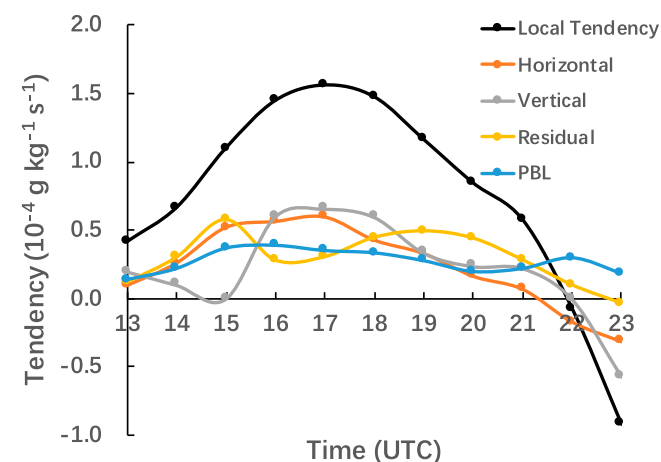

(e)

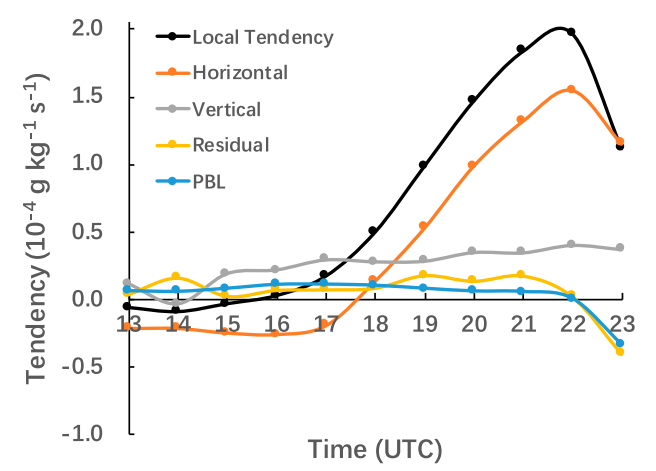

(b)
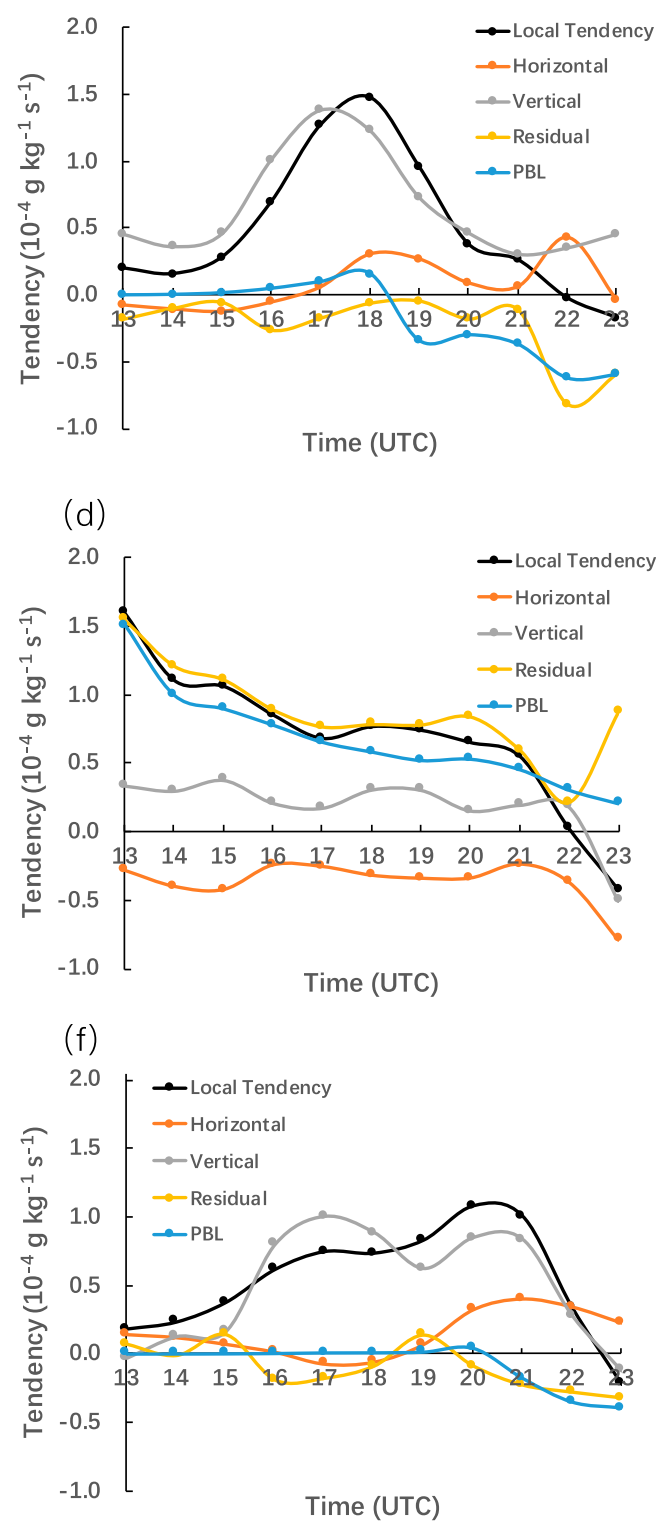

FIG. 13. (a) Evolution of water vapor mixing ratio $\left(q_{v}, \mathrm{~g} \mathrm{~kg}^{-1}\right)$ and relative humidity $(\mathrm{RH}, \%)$ at $950 \mathrm{hPa}$ averaged over regions A-E in Fig. 11 during the period 1300-2300 UTC 21 Jun 2018. (b) Evolution of area-averaged local tendency (black line) of $q_{v}\left(\mathrm{~g} \mathrm{~kg}^{-1} \mathrm{~s}^{-1}\right)$ at $950 \mathrm{hPa}$, and its components including horizontal transport (red line), vertical transport (gray line), residual term (orange line), and tendency caused by vertical turbulence mixing in the boundary layer (blue line) over region A of Fig. 11. (c)-(f) As in (b), but for regions B-E, respectively. The CI timing (2100 UTC 21 Jun) is marked by a triangle in (a).

(Fig. 13d). Region $\mathrm{C}$ is in proximity to the warm center of SST $(\sim 304 \mathrm{~K})$ that produces a large upward moisture flux (QFX) at the sea surface (Fig. 14). High QFX is a source of vertical turbulence mixing of moisture in the marine boundary layer which enhances the moist tongue over the ocean. We have illustrated low-level moistening in a warm moist tongue by mesoscale ascent, horizontal transport as well as vertical turbulence mixing. In turns, the warm moist tongue with a lateral variation of the convective boundary layer buoyancy might be effective in generating vertical motion in the presence of nocturnal LLJs, which is consistent with the theory of Shapiro et al. (2018).

As for the UCG process, in addition to the effect of cold pools, which will be discussed in Part II, CI subsequently and continuously occurs on the west and east 

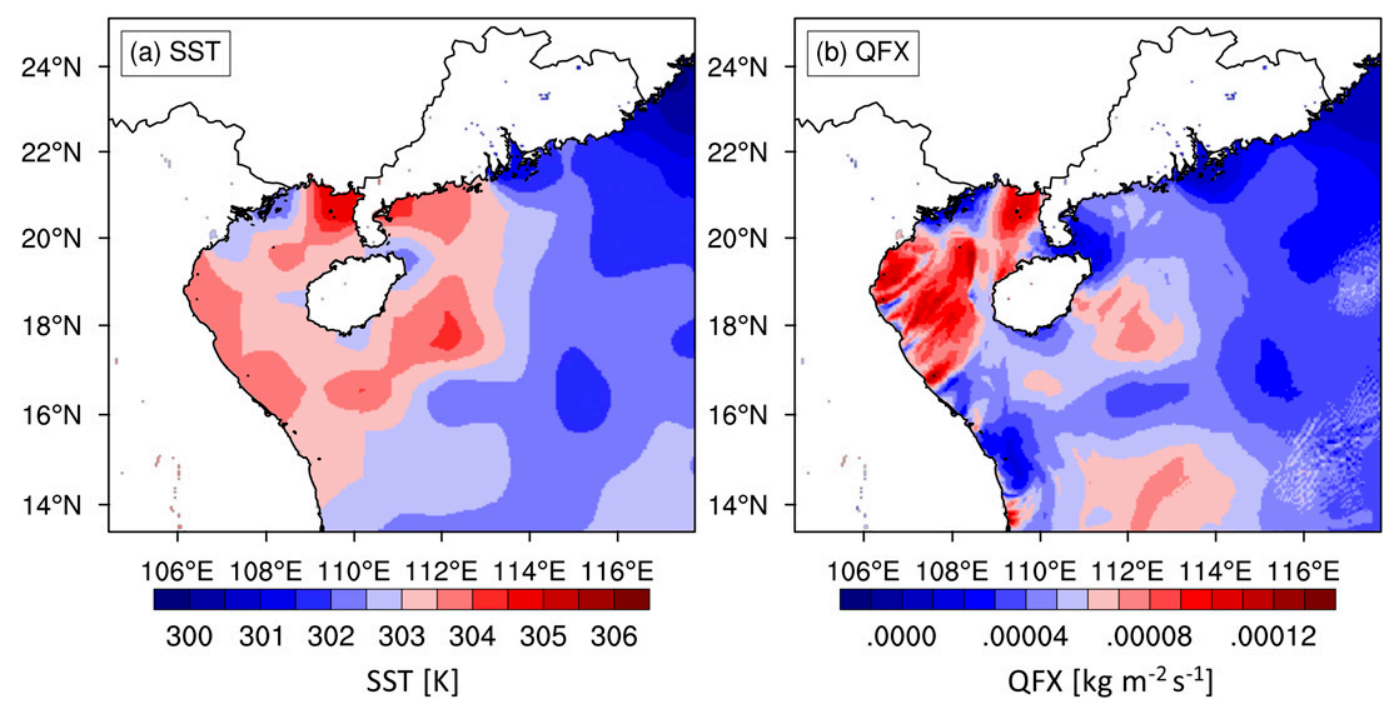

FIG. 14. Horizontal distribution of (a) SST and (b) QFX at the sea surface at 1800 UTC 21 Jun 2018.

sides of the original CI location along the coast (e.g., region $\mathrm{D}$ and region $\mathrm{E}$ ) and thus results in the growth of SW-NE-oriented MCS (Figs. 3 and 4). The differences in $\mathrm{CI}$ timing along the coast is a result of varying thermodynamic condition. The increase of water vapor in regions $D$ and $E$ is delayed by $3-4 \mathrm{~h}$, compared to that in region $\mathrm{A}$, and therefore $\mathrm{CI}$ in regions $\mathrm{D}$ and $\mathrm{E}$ occurs later. The convection cells, in close proximity to each other, then merged and organized into a larger MCS. The moisture budget in region D (Fig. 13e) shows the dominant term for the moisture increase is the horizontal transport term which becomes significant at 2100 UTC; this happens because the moist tongue gradually moves to the north and affects region D later (Fig. 11). For region E where moisture increases later too, the horizontal and vertical transport terms jointly contribute to the local change of moisture (Fig. 13f). The delayed vertical transport is related to the eastward movement of the MBLJ (Fig. 9) and eastward expansion of the moist tongue (Fig. 11). The movement of the MBLJ and moist tongue is attributed to the southeasterly steering flow (Figs. 7a,b).

Since the SST over the NSCS may influence CI by the low-level moistening processes diagnosed above, sensitivity experiments with regard to SST are further conducted to confirm it. Given that the SST over the NSCS varies spatially from 300 to $304 \mathrm{~K}$ (Fig. 14a), we perform LowSST and HighSST runs where the SST is modified to a constant value of 300 and $304 \mathrm{~K}$, respectively. Figure 15 shows that, compared to the control run, convection initiation and growth occur later and earlier in the LowSST and HighSST runs, respectively. The reason is because the moist tongue over the NSCS increases as the SST increases (Figs. 16a-c), and the enhanced moist tongue is favorable to CI near the coast by thermodynamic processes. As shown in Fig. 16, the MBLJ is intensified (weakened) in LowSST (HighSST). This effect on MBLJ intensity is due to vertical turbulence mixing (not shown) which is stronger (weaker) in HighSST (LowSST). Although the higher SST inhibits convection by inducing weaker mesoscale lifting at terminus of a weaker MBLJ, the higher SST promotes convection by the incursion of an enhanced moist tongue to the coast. In general, the thermodynamic (moisture) effect is more significant than the dynamic effect, regarding SST sensitivity.

\section{Ensemble simulations}

To confirm the dynamic and thermodynamic effects of the MBLJ proposed above, 20 ensemble members are collectively analyzed. Figure 17 displays the radar composite reflectivity at 2100 UTC from 20 ensemble members. Based on their CI, ensemble members are classified into two groups: (i) good members in which $\mathrm{CI}$ is similar to that in the control run in terms of timing and location or (ii) bad members in which $\mathrm{CI}$ is weaker or occurs later than the control run. The criterion for good or bad members is whether radar reflectively greater than $35 \mathrm{~dB} Z$ occurs near Lufeng at 2100 UTC 21 June 2018. The two groups are compared in atmospheric background environments to elucidate the role of the MBLJ.

Figure 18 shows the composites of $950-\mathrm{hPa}$ winds averaged from good or bad members. The MBLJ tends to be stronger in the good members than bad members (cf. Figs. 18a,b and 18d,e). The differences in winds (vectors) at $950 \mathrm{hPa}$ between good and bad members (Figs. 18c,f) show that onshore low-level winds over the 


\section{Control}
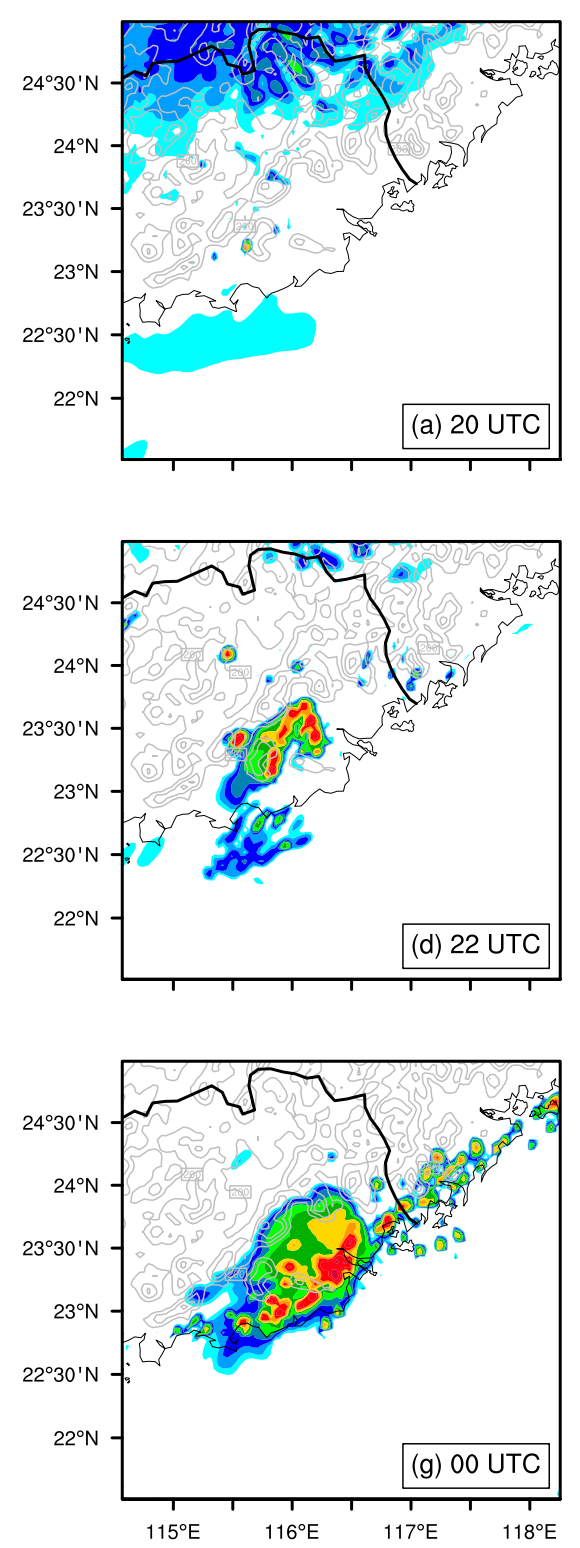

LowSST
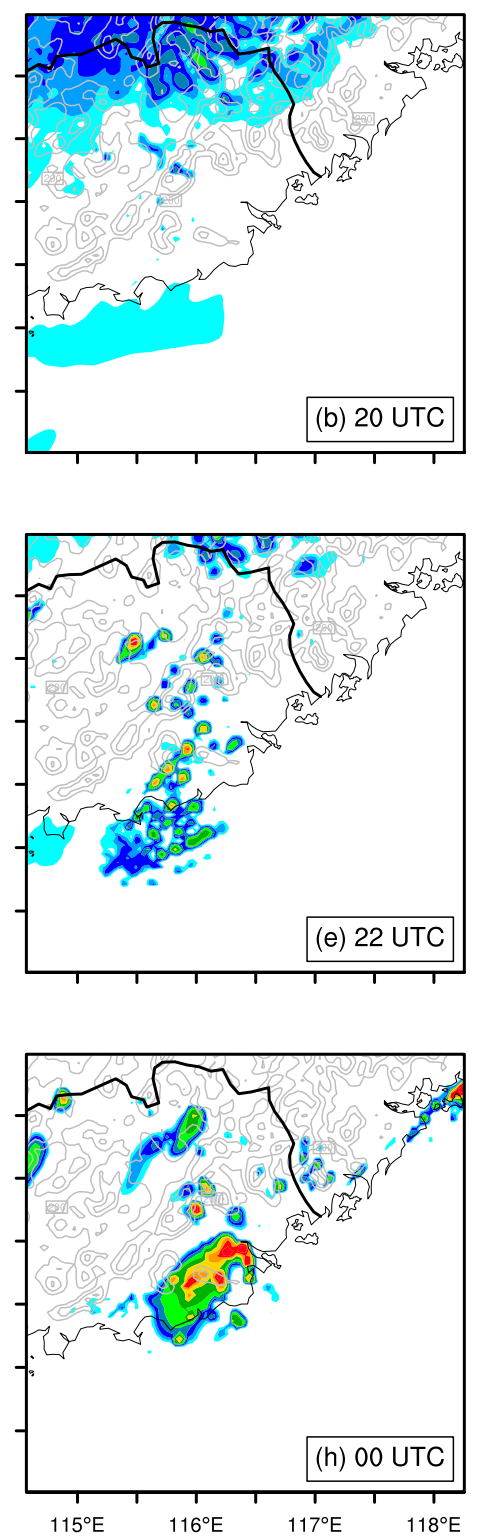

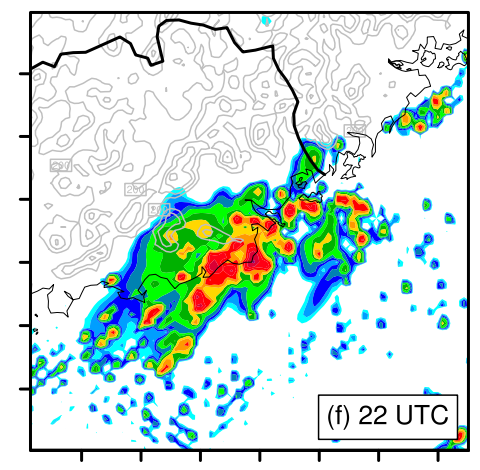

HighSST
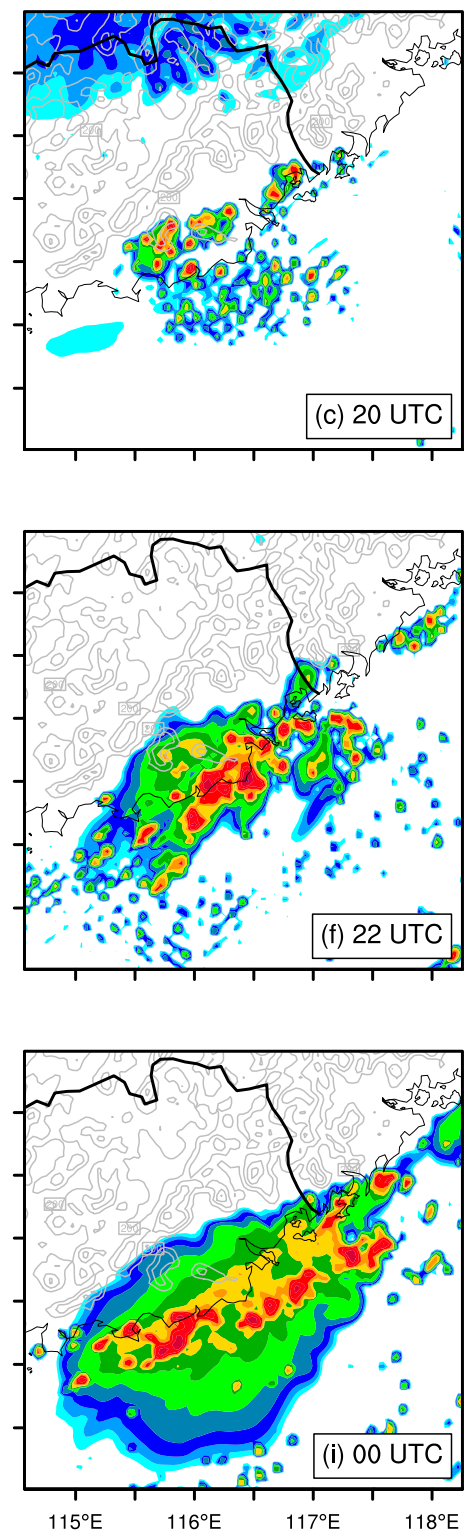

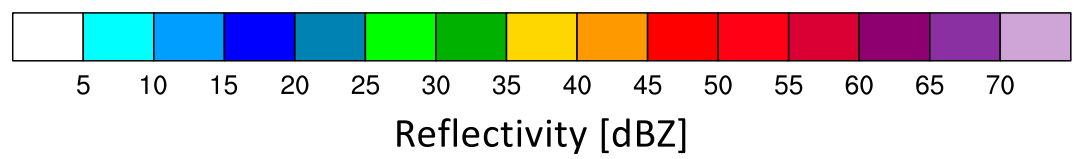

FIG. 15. Simulated radar composite reflectivity from (a),(d),(g) the control run; (b),(e),(h) the LowSST run; and (c),(f),(i) the HighSST run at (a)-(c) 2000 UTC 21 Jun; (d)-(f) 2200 UTC 21 Jun; and (g)-(i) 0000 UTC 22 Jun 2018. Gray solid contours indicate terrain height $($ contour interval $=200 \mathrm{~m})$. 

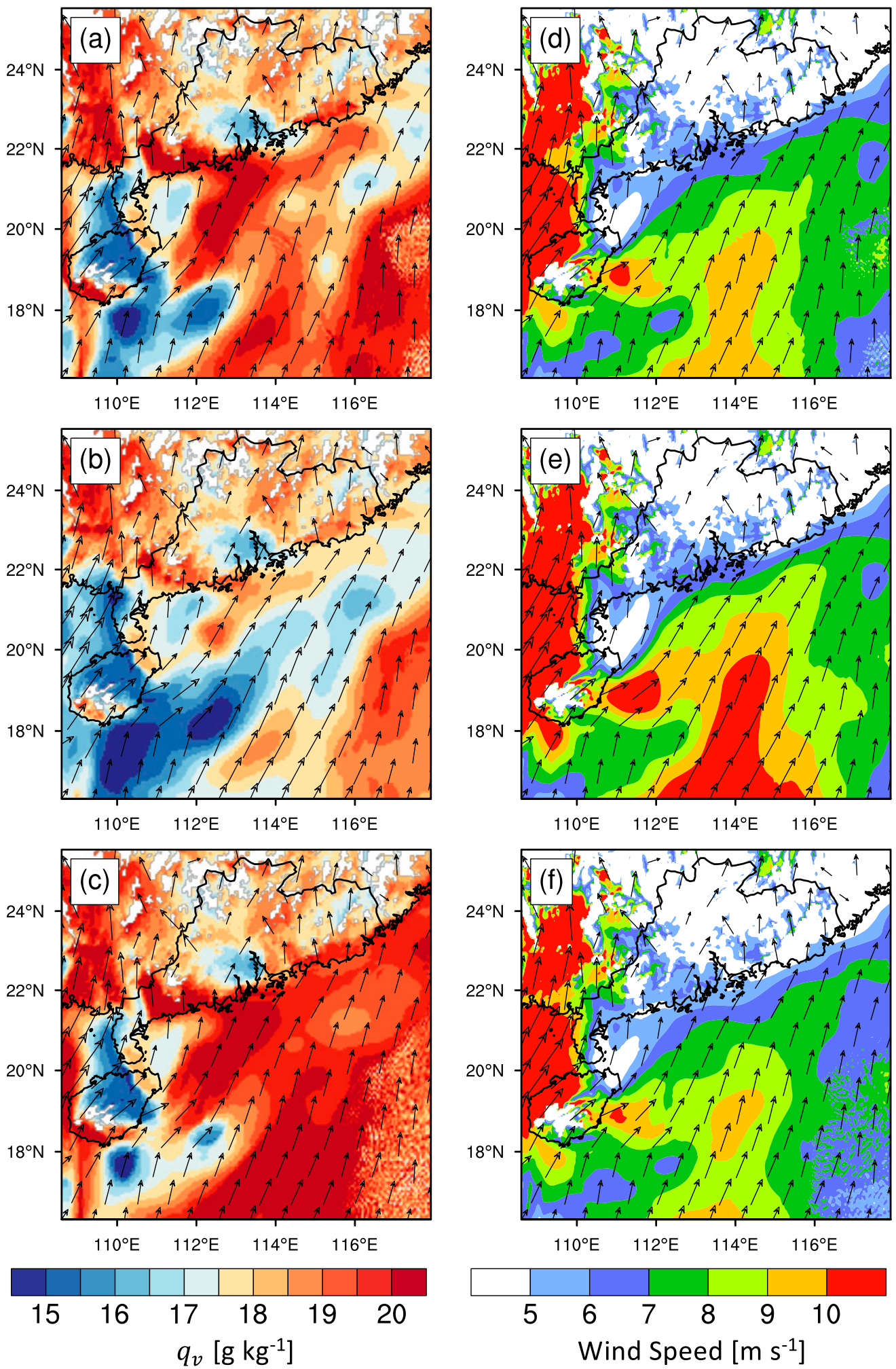

FIG. 16. Distribution of (a)-(c) water vapor mixing ratio (shaded) and (d)-(f) wind speed (shaded) together with the horizontal wind vectors at $950 \mathrm{hpa}$ at 1800 UTC 21 Jun 2018 from (a),(d) the control run; (b),(e) the LowSST run; and (c),(f) the HighSST run. 


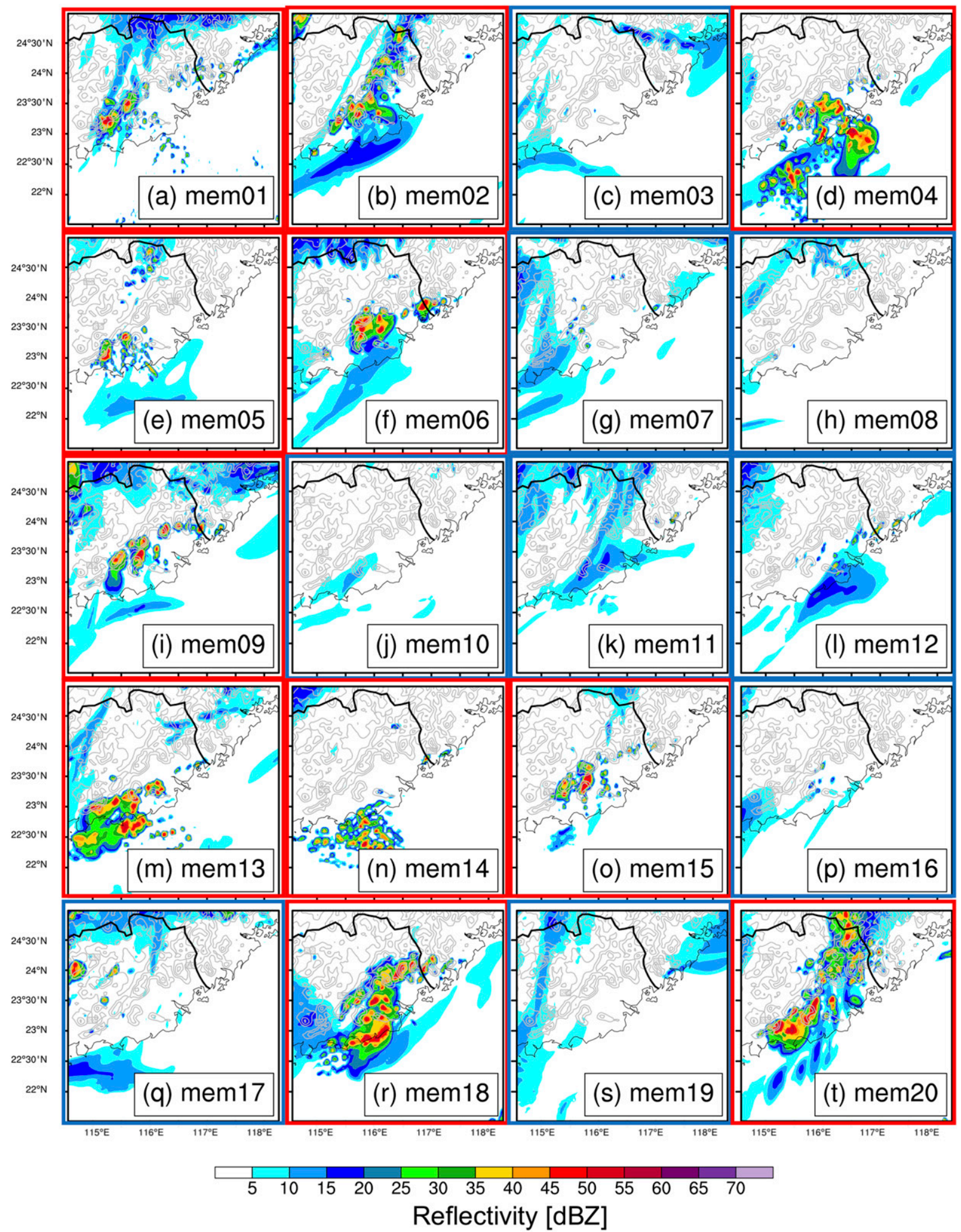

FIG. 17. Radar composite reflectivity (dBZ) from the (a)-(t) mem01-mem20 runs at 2100 UTC 21 Jun 2018. Gray solid contours indicate terrain height (contour interval $=200 \mathrm{~m})$. Good and bad members are outlined by red and blue squares, respectively. 

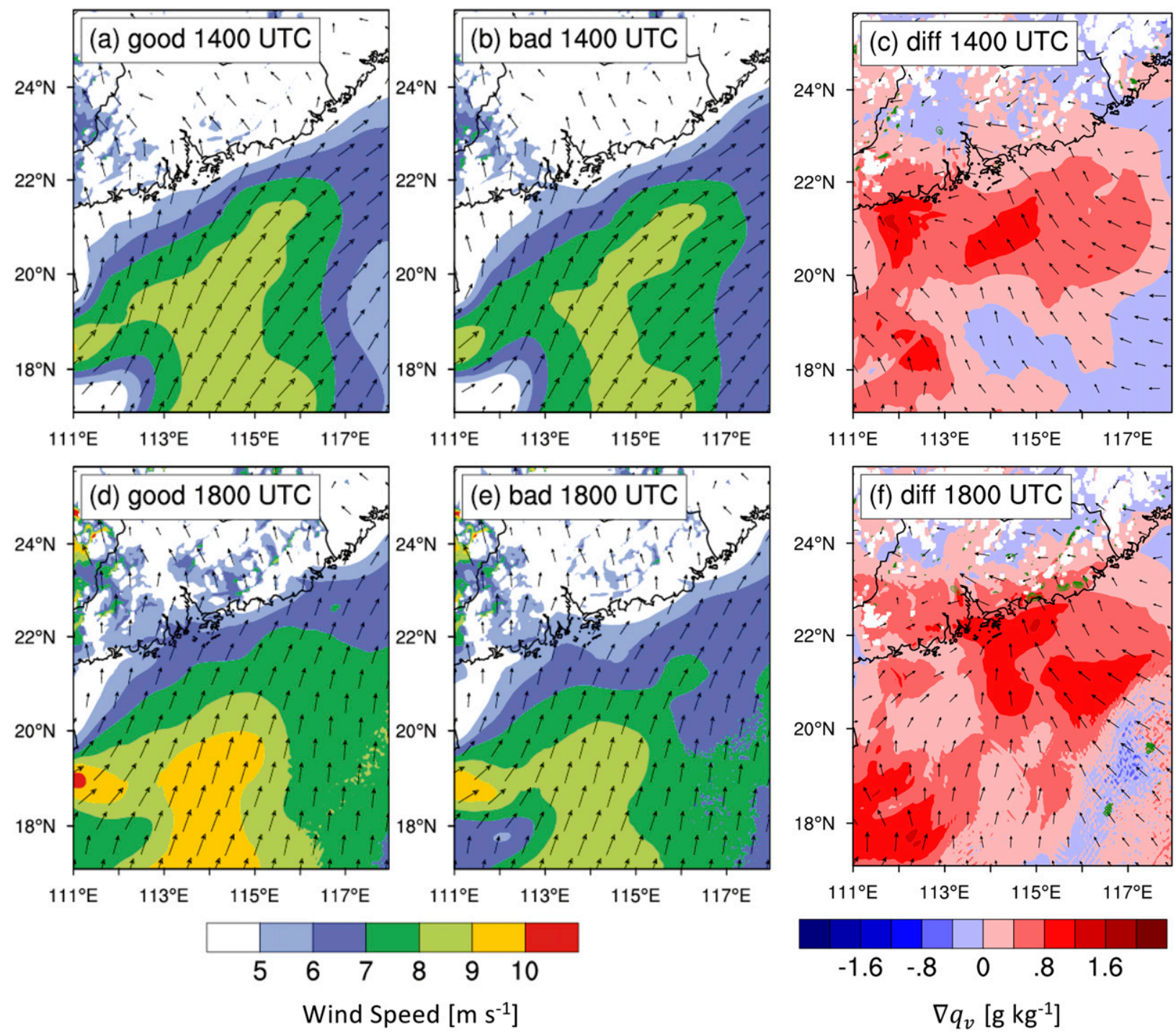

FIG. 18. Composite of wind speed (shaded) and vectors at $950 \mathrm{hPa}$ averaged from (a),(d) good members and (b),(e) bad members, and (c)-(f) the differences in water vapor mixing ratio at $950 \mathrm{hPa}$ (shaded), vertical velocity at $975 \mathrm{hPa}$ (green contours indicate $>0.01 \mathrm{~m} \mathrm{~s}{ }^{-1}$ ), and wind vectors at $950 \mathrm{hPa}$ between good members and bad members at (a)-(c) 1400 and (d)-(f) 1800 UTC 21 Jun 2018.

ocean perpendicular to the coasts (southeasterly) is favorable to CI. It is because stronger onshore low-level winds encounter coastal terrain and induce stronger upward motions near the coastal terrain (Fig. 18) by orographic lifting and coastal convergence. The coastal terrain and coastline play dynamic and thermodynamic roles in CI and UCG, which will be investigated in detail in Part II. Furthermore, Figs. 18c and 18f show that the 950-hPa moisture content over the ocean near the coast in good members is larger than that in bad members, suggesting a stronger simulated moist tongue in good members.

Figure 19 presents the scatter diagram of horizontally averaged water vapor mixing ratio and wind speeds at $950 \mathrm{hPa}$ horizontally averaged in regions $\mathrm{A}$ and $\mathrm{B}$ among ensemble members. A majority of the good members exhibit features with higher wind speeds and higher water mixing ratio compared to the worse members, which is consistent with what we expect (stronger MBLJ and moisture tongue are more favorable to CI and UCG near the coast).

We further explore the moisture budgets among the ensemble members to explain varying moisture increases. Since the vertical transport term of water vapor mixing ratio is a main contributor in low-level moistening for region A as shown in Fig. 13b, we concentrate on the vertical transport terms among those ensemble members. Figure 20 clearly shows that the vertical transport term reaches its peak earlier in the good 


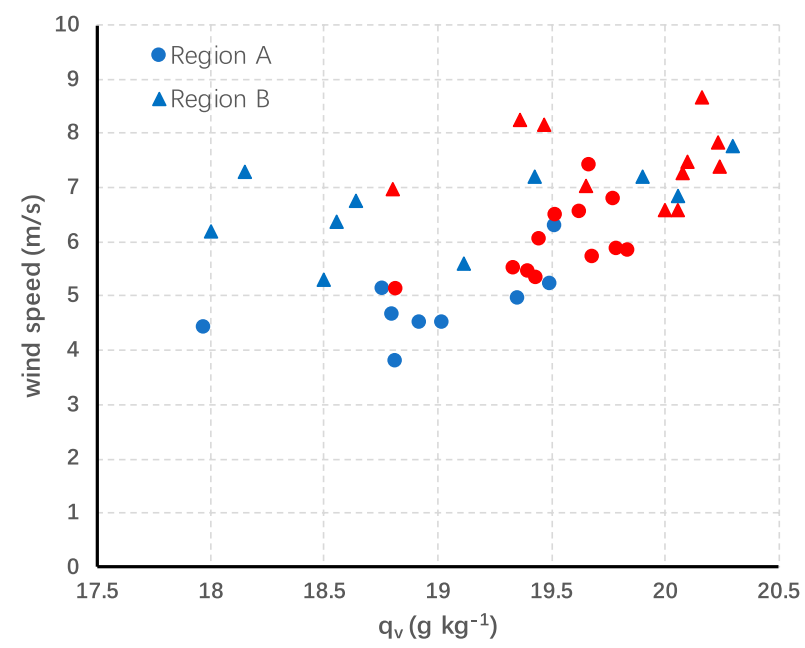

FIG. 19. Scatter diagram of water vapor mixing ratio $\left(\mathrm{g} \mathrm{kg}^{-1}\right)$ and wind speed $\left(\mathrm{m} \mathrm{s}^{-1}\right)$ at $950 \mathrm{hPa}$ averaged in regions $\mathrm{A}$ and $\mathrm{B}$ at 1800 UTC 21 Jun 2018. Red and blue makers indicate good and bad members, respectively.

members than in the bad members and thereby moisture is obtained earlier and accumulates more in the good members prior to CI. Additionally, the water vapor mixing ratio at the time of $\mathrm{CI}$ depends on the initial water vapor mixing ratio in the model at $1200 \mathrm{UTC}\left(q_{0}\right)$ as well as the accumulated vertical transport term during 1200-1800 UTC $\left(q_{\mathrm{vt}}\right)$. The scatter diagram of $q_{0}$ and $q_{\mathrm{vt}}$ at $950 \mathrm{hPa}$ (Fig. 20b) shows that good members are generally characterized by either high $q_{0}\left(>18.0 \mathrm{~g} \mathrm{~kg}^{-1}\right)$ or high $q_{\mathrm{vt}}\left(>1.5 \mathrm{~g} \mathrm{~kg}^{-1}\right)$. In summary, the stronger MBLJs with enhanced low-level moistening in the warm moist tongue along its northeastern edge and terminus are more favorable to $\mathrm{CI}$ at the coast near Lufeng.

\section{Summary}

In the present study, we examined a case of coastal CI and its subsequent UCG in a heavy rainfall event in South China (21-22 June 2018), mainly concentrating on the dynamic and thermodynamic effects of a marine boundary layer jet (MBLJ) from convection-permitting simulations. The convection was initiated at the east coast of Guangdong province (near Lufeng), which was located hundreds of kilometers away from a shear line and a low pressure vortex at $850 \mathrm{hPa}$. The newborn convection gradually developed into a larger SW-NE-oriented linear convective system along the coast, which we called upscale convective growth (UCG). The convection initiation, growth and relevant atmospheric environment can be well reproduced by convection-permitting simulations and this provides a good opportunity to explore the physical mechanisms.

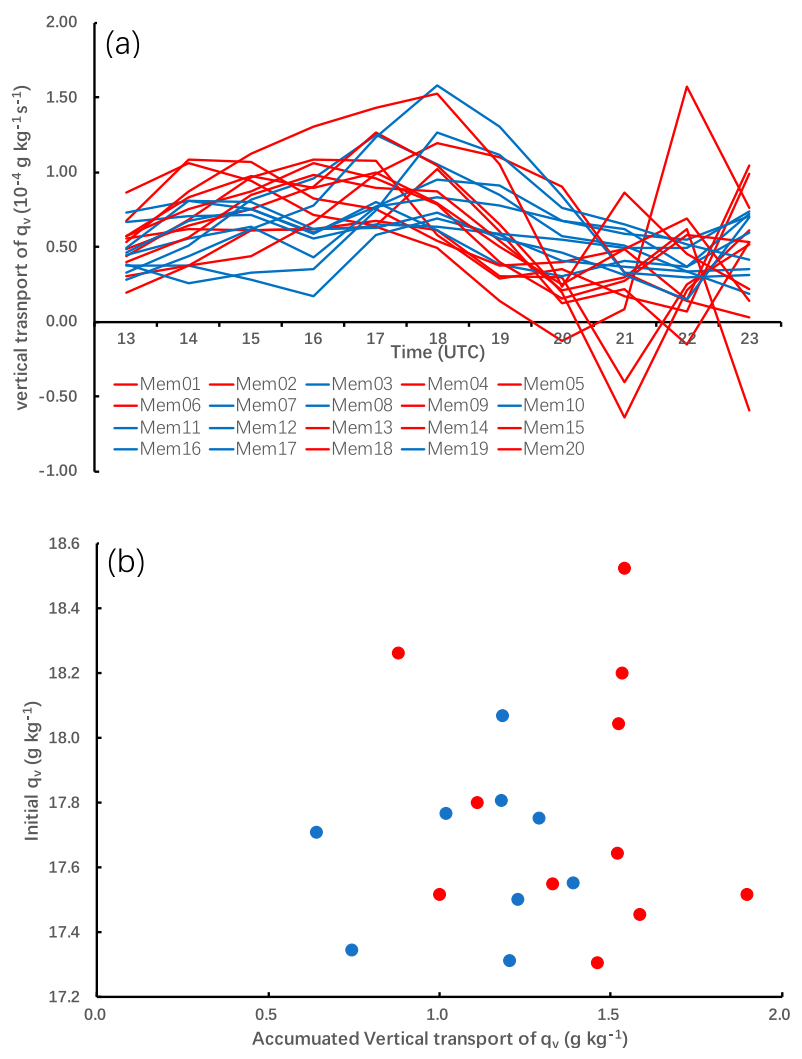

FIG. 20. (a) Evolution of the vertical transport of water vapor mixing ratio $\left(q_{v}, \mathrm{~g} \mathrm{~kg}^{-1} \mathrm{~s}^{-1}\right)$ at $950 \mathrm{hPa}$ averaged over region $\mathrm{A}$ in Fig. 11 during 1300-2300 UTC 21 Jun 2018 from the mem01mem 20 runs. (b) Scatter diagram of accumulated vertical transport of $q_{v}\left(\mathrm{~g} \mathrm{~kg}^{-1}\right)$ during 1200-1800 UTC and initial water vapor mixing ratio $\left(\mathrm{g} \mathrm{kg}^{-1}\right)$ at 1200 UTC 21 Jun 2018 averaged in region A. Red and blue lines in (a) or dots in (b) indicate good and bad members, respectively.

CI and subsequent UCG near the coast are situated downstream of a southwesterly low-level jet over the NSCS. The LLJ speed maximized at $950 \mathrm{hPa}$ in the marine boundary layer, which we regard as the MBLJ. The analysis of the numerical simulation indicates that the spatial structure and temporal variation of the MBLJ exert a significant influence on CI and UCG by its influence on mesoscale ascent and low-level moistening near the south coast of China. The major findings in this study are summarized in the schematic diagram based on the main aspects of dynamics and thermodynamics (Fig. 21).

Mesoscale ascent is apparent on the northwestern and northeastern edges and on the terminus of the MBLJ, where large gradient zones of horizontal wind at $950 \mathrm{hPa}$ or convergence exist. The intensity and location of the mesoscale ascent vary along with the evolution of the MBLJ. In the late afternoon, the southwesterly MBLJ is relatively weak, and thereby the mesoscale ascent on the edges of the MBLJ is correspondingly weak. After 


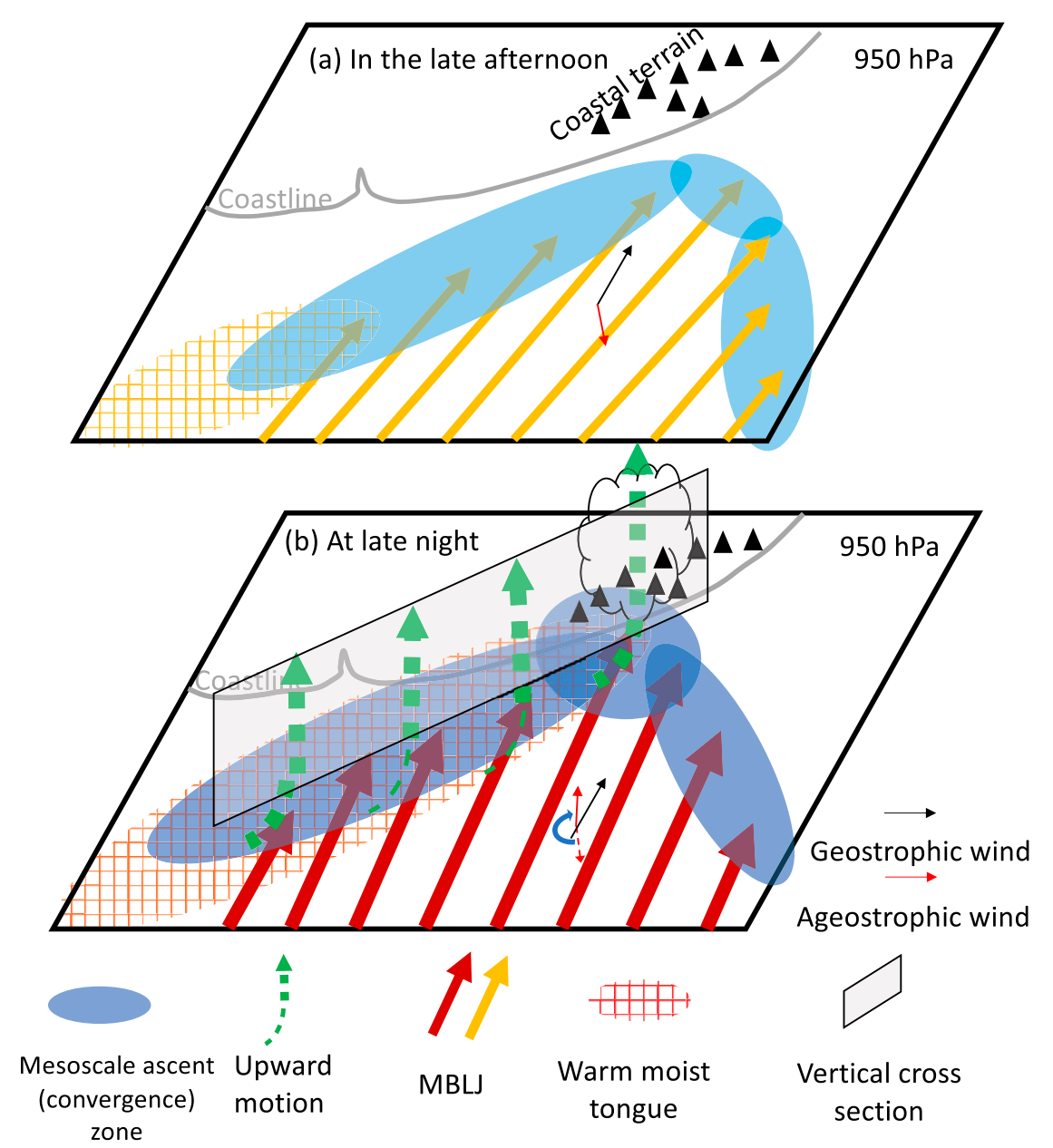

FIG. 21. Schematic diagram depicting the convective initiation and growth near the coast associated with a varying MBLJ. Mesoscale ascent on the northwestern and northeastern edges and terminus of the MBLJ is enhanced and moved as the MBLJ develops in intensity and evolves from southwesterly to nearly southerly, which supports CI and UCG near the coast dynamically. A warm moist tongue over the ocean is also strengthened by low-level moistening associated with the MBLJ-driven mesoscale ascent overlaying high SST.

midnight, the MBLJ intensifies and turns to nearly southerly. The mesoscale ascent on the edges of the MBLJ becomes stronger as the MBLJ intensifies. Hence, CI and UCG near the coast are promoted by the strong mesoscale ascent particularly on the northwestern edges and terminus of the MBLJ. Through analysis of geostrophic and ageostrophic winds in the MBLJ, the nocturnal development of the MBLJ is shown to be linked to an inertial oscillation associated with the large-scale sea-breeze circulation

A warm moist tongue gradually develops over the NSCS and extends northeastward to the coast. The warm moist tongue is approximately located at the northwestern edge of the MBLJ and overlays the area of high SST. Strong vertical turbulence mixing of moisture in the marine boundary layer greatly humidified the marine boundary layer in proximity to high SST area. Subsequently, the moisture in the marine boundary layer is horizontally transported northeastward along with the MBLJ as well as being vertically transported by the mesoscale ascent. Compared to the horizontal transport, the vertical transport becomes a main contributor to low-level moistening near the CI location. These processes contribute to the evolution from a subsaturated condition in the lower layer to deep conditionally unstable layers with high relative humidity that support CI. Since low-level moistening occurs several hours later on either side of Lufeng along the coast, subsequent CI occurrences appear later than the first CI near Lufeng. The sequence of CI contributes to the growth of a SW-NE-oriented linear MCS along the coast. Sensitivity experiments with varying SST suggest that a higher SST accompanying by a stronger moist tongue is more conductive to $\mathrm{CI}$ at the coast. 
A total of 20-member ensemble simulations are conducted using the WRF Model initialized with the Global Ensemble Forecast System (GEFS) data to further confirm that the effect of the MBLJ is associated with mesoscale ascent and low-level moisture. Two groups of good members and bad members are classified based on their ability to produce the observed CI. Compared to the bad members, the good members have a stronger MBLJ with enhanced low-level moistening and lifting along its northeastern edge and terminus, which readily leads to CI near the coast.

This study is the first part of a two-part series study on convection initiation and growth at the coast of South China. In the present study (Part I), our focus is on the role of MBLJ, which is a mesoscale forcing. More detailed local meso- to small-scale forcings including terrain effects and cold pools in the same case will be investigated in Part II. In the future, more cases of CI and UCG near the coast of South China will be studied to clarify various mechanisms, which may vary in the other atmospheric conditions. Owing to a lack of observations in the NSCS, upper-air soundings deployed from scientific research ships or dropsondes obtained from aircrafts are required to sample the spatial and temporal features of the MBLJ and to evaluate the capability of numerical simulations and forecast skill of the MBLJ.

Acknowledgments. This study was supported by the National Key Research and Development Program of China (Grant 2018YFC1507402), the National Natural Science Foundation of China (Grants 41875055, 41861164027, and 41775094), Guangzhou Science and Technology Plan Projects (202002030346), the Fundamental Research Funds for the Central Universities (19lgzd08), and the Young Elite Scientists Sponsorship Program by CAST (2018QNRC001). The authors are thankful to Dr. Richard Rotunno from NCAR for his help in improving the manuscript.

\section{REFERENCES}

Astling, E. G., J. Paegle, E. Miller, and C. J. O’Brien, 1985: Boundary layer control of nocturnal convection associated with a synopticscale system. Mon. Wea. Rev., 113, 540-552, https://doi.org/ 10.1175/1520-0493(1985)113<0540:BLCONC>2.0.CO;2.

Bai, L., G. Chen, and L. Huang, 2020a: Image processing of radar mosaics for the climatology of convection initiation in South China. J. Appl. Meteor. Climatol., 59, 65-81, https://doi.org/ 10.1175/JAMC-D-19-0081.1.

,-- , and,$- 2020 \mathrm{~b}$ : Convection initiation in monsoon coastal areas (South China). Geophys. Res. Lett., 47, e2020GL087035, https://doi.org/10.1029/2020GL087035.

Barnes, S. L., 1964: A technique for maximizing details in numerical weather map analysis. J. Appl. Meteor., 3, 396-409, https://doi.org/ 10.1175/1520-0450(1964)003<0396:ATFMDI > 2.0.CO;2.
Blackadar, A. K., 1957: Boundary layer wind maxima and their significance for the growth of nocturnal inversions. Bull. Amer. Meteor. Soc., 38, 283-290, https://doi.org/10.1175/ 1520-0477-38.5.283.

Bonner, W. D., 1968: Climatology of the low level jet. Mon. Wea. Rev., 96, 833-850, https://doi.org/10.1175/1520-0493(1968) 096<0833:COTLLJ $>2.0$.CO;2.

Chen, G., W. Sha, T. Iwasaki, and Z. Wen, 2017: Diurnal cycle of a heavy rainfall corridor over East Asia. Mon. Wea. Rev., 145, 3365-3389, https://doi.org/10.1175/MWR-D-16-0423.1.

- R. Lan, W. Zeng, H. Pan, and W. Li, 2018: Diurnal variations of rainfall in surface and satellite observations at the monsoon coast (South China). J. Climate, 31, 1703-1724, https://doi.org/ 10.1175/JCLI-D-17-0373.1.

Chen, G. T. J., and C. C. Yu, 1988: Study of low-level jet and extremely heavy rainfall over northern Taiwan in the mei-yu season. Mon. Wea. Rev., 116, 884-891, https://doi.org/10.1175/ 1520-0493(1988)116<0884:SOLLJA >2.0.CO;2.

Chen, S. J., Y. H. Kuo, W. Wang, Z. Y. Tao, and B. Cui, 1998: A modeling case study of heavy rainstorms along the mei-yu front. Mon. Wea. Rev., 126, 2330-2351, https://doi.org/10.1175/ 1520-0493(1998)126<2330:AMCSOH >2.0.CO;2.

Chen, X., K. Zhao, and M. Xue, 2017: Influence of monsoonal wind speed and moisture content on intensity and diurnal variations of the mei-yu season coastal rainfall over south China. J. Atmos. Sci., 74, 2835-2856, https://doi.org/10.1175/JAS-D-17-0081.1.

Chen, Y.-L., X. A. Chen, and Y.-X. Zhang, 1994: A diagnostic study of the low-level jet during TAMEX IOP 5. Mon. Wea. Rev., 122, 2257-2284, https://doi.org/10.1175/1520-0493(1994) 122<2257:ADSOTL>2.0.CO;2.

Chou, L. C., C.-P. Chang, and R. T. Williams, 1990: A numerical simulation of the mei-yu front and the associated low-level jet. Mon. Wea. Rev., 118, 1408-1428, https://doi.org/10.1175/ 1520-0493(1990)118<1408:ANSOTM>2.0.CO;2.

Coniglio, M. C., J. Y. Hwang, and D. J. Stensrud, 2010: Environmental factors in the upscale growth and longevity of MCSs derived from Rapid Update Cycle analyses. Mon. Wea. Rev., 138, 3514-3539, https://doi.org/10.1175/2010MWR3233.1.

— S. F. Corfidi, and J. S. Kain, 2011: Environment and early evolution of the 8 May 2009 derecho-producing convective system. Mon. Wea. Rev., 139, 1083-1102, https://doi.org/10.1175/ 2010MWR3413.1.

Davis, C. A., K. W. Manning, R. E. Carbone, S. B. Trier, and J. D. Tuttle, 2003: Coherence of warm-season continental rainfall in numerical weather prediction models. Mon. Wea. Rev., 131, 2667-2679, https://doi.org/10.1175/1520-0493(2003)131<2667: COWCRI>2.0.CO;2.

Du, Y., and R. Rotunno, 2014: A simple analytical model of the nocturnal low-level jet over the Great Plains of the United States. J. Atmos. Sci., 71, 3674-3683, https://doi.org/10.1175/ JAS-D-14-0060.1.

_ , and G. Chen, 2018: Heavy rainfall associated with double low-level jets over southern China. Part I: Ensemble-based analysis. Mon. Wea. Rev., 146, 3827-3844, https://doi.org/10.1175/ MWR-D-18-0101.1.

—, and G. X. Chen, 2019a: Heavy rainfalls associated with double low-level jets over southern China. Part II: Convection initiation. Mon. Wea. Rev., 147, 543-565, https://doi.org/10.1175/ MWR-D-18-0102.1.

_, and — 2019b: Climatology of low-level jets and their impact on rainfall over southern China during early-summer rainy season. J. Climate, 32, 8813-8833, https://doi.org/10.1175/ JCLI-D-19-0306.1. 
—, Q. H. Zhang, Y. Ying, and Y. M. Yang, 2012: Characteristics of low-level jets in Shanghai during the 2008-2009 warm seasons as inferred from wind profiler radar data. J. Meteor. Soc. Japan, 90, 891-903, https://doi.org/10.2151/jmsj.2012-603.

, _ - Y. L. Chen, Y. Y. Zhao, and X. Wang, 2014: Numerical simulations of spatial distributions and diurnal variations of low-level jets in China during early summer. J. Climate, 27, 5747-5767, https://doi.org/10.1175/JCLI-D-13-00571.1.

—, R. Rotunno, and Q. H. Zhang, 2015: Analysis of WRFsimulated diurnal boundary-layer winds in eastern China using a simple 1D model. J. Atmos. Sci., 72, 714-727, https:// doi.org/10.1175/JAS-D-14-0186.1.

Fedorovich, E., J. A. Gibbs, and A. Shapiro, 2017: Numerical study of nocturnal low-level jets over gently sloping terrain. J. Atmos. Sci., 74, 2813-2834, https://doi.org/10.1175/JAS-D-17-0013.1.

Gebauer, J. G., A. Shapiro, E. Fedorovich, and P. Klein, 2018: Convection initiation caused by heterogeneous low-level jets over the Great Plains. Mon. Wea. Rev., 146, 2615-2637, https:// doi.org/10.1175/MWR-D-18-0002.1.

Geerts, B., and Coauthors, 2017: The 2015 Plains Elevated Convection at Night field project. Bull. Amer. Meteor. Soc., 98, 767-786, https://doi.org/10.1175/BAMS-D-15-00257.1.

Haghi, K. R., D. B. Parsons, and A. Shapiro, 2017: Bores observed during IHOP_2002: The relationship of bores to the nocturnal environment. Mon. Wea. Rev., 145, 3929-3946, https://doi.org/ 10.1175/MWR-D-16-0415.1.

Holton, J. R., 1967: The diurnal boundary layer wind oscillation above sloping terrain. Tellus, 19A, 199-205, https://doi.org/ 10.1111/j.2153-3490.1967.tb01473.x.

Hong, S. Y., Y. Noh, and J. Dudhia, 2006: A new vertical diffusion package with an explicit treatment of entrainment processes. Mon. Wea. Rev., 134, 2318-2341, https://doi.org/10.1175/ MWR3199.1.

Huang, W. R., and J. C. L. Chan, 2011: Maintenance mechanisms for the early-morning maximum summer rainfall over Southeast China. Quart. J. Roy. Meteor. Soc., 137, 959-968, https://doi.org/ 10.1002/qj.815.

,$- \ldots$, and S. Y. Wang, 2010: A planetary-scale land-sea breeze circulation in East Asia and the western North Pacific. Quart. J. Roy. Meteor. Soc., 136, 1543-1553, https://doi.org/ 10.1002/qj.663.

Iacono, M. J., J. S. Delamere, E. J. Mlawer, M. W. Shepard, S. A. Clough, and W. D. Collins, 2008: Radiative forcing by longwave greenhouse gases: Calculations with the AER radiative transfer models. J. Geophys. Res., 113, D13103, https://doi.org/ 10.1029/2008JD009944.

Jiménez, P. A., J. Dudhia, J. F. González-Rouco, J. Navarro, J. P. Montávez, and E. García-Bustamante, 2012: A revised scheme for the WRF surface layer formulation. Mon. Wea. Rev., 140, 898-918, https://doi.org/10.1175/MWR-D-11-00056.1.

Joyce, R. J., J. E. Janowiak, P. A. Arkin, and P. P. Xie, 2004: CMORPH: A method that produces global precipitation estimates from passive microwave and infrared data at high spatial and temporal resolution. J. Hydrometeor., 5, 487-503, https:// doi.org/10.1175/1525-7541(2004)005<0487:CAMTPG > 2.0.CO;2.

Kain, J. S., 2004: The Kain-Fritsch convective parameterization: An update. J. Appl. Meteor., 43, 170-181, https://doi.org/ 10.1175/1520-0450(2004)043<0170:TKCPAU>2.0.CO;2.

Keene, K. M., and R. S. Schumacher, 2013: The bow and arrow mesoscale convective structure. Mon. Wea. Rev., 141, 1648-1672, https://doi.org/10.1175/MWR-D-12-00172.1.

Li, H., Q. Wan, D. Peng, X. Liu, and H. Xiao, 2020: Multiscale analysis of a record-breaking heavy rainfall event in Guangdong,
China. Atmos. Res., 232, 104703, https://doi.org/10.1016/ j.atmosres.2019.104703.

Li, Z., Y. Luo, Y. Du, and J. C. L. Chan, 2020: Statistical characteristics of pre-summer rainfall over south China and associated synoptic conditions. J. Meteor. Soc. Japan, 98, 213-233, https:// doi.org/10.2151/jmsj.2020-012.

Liu, X., Y. Luo, Z. Guan, and D.-L. Zhang, 2018: An extreme rainfall event in coastal South China during SCMREX-2014: Formation and roles of rainband and echo trainings. J. Geophys. Res. Atmos., 123, 9256-9278, https://doi.org/10.1029/2018JD028418.

Livneh, B., P. J. Restrepo, and D. P. Lettenmaier, 2011: Development of a unified land model for prediction of surface hydrology and land-atmosphere interactions. J. Hydrometeor., 12, 1299-1320, https://doi.org/10.1175/2011JHM1361.1.

Luo, Y., 2017: Advances in understanding the early-summer heavy rainfall over south China. The Global Monsoon System: Research and Forecast, 3rd ed. C. P. Chang et al., Eds., World Scientific Series on Asia-Pacific Weather and Climate, Vol. 9, World Scientific, 215-226.

— , and Coauthors, 2017: The Southern China Monsoon Rainfall Experiment (SCMREX). Bull. Amer. Meteor. Soc., 98, 999-1013, https://doi.org/10.1175/BAMS-D-15-00235.1.

_ , Y. J. Wang, H. Y. Wang, Y. J. Zheng, and H. Morrison, 2010: Modeling convective-stratiform precipitation processes on a $\mathrm{Mei}-\mathrm{Yu}$ front with the weather research and forecasting model: Comparison with observations and sensitivity to cloud microphysics parameterizations. J. Geophys. Res., 115, D18117, https://doi.org/10.1029/2010JD013873.

_ , and Coauthors, 2020: Science and prediction of heavy rainfall over China: Research progress since the reform and openingup of New China. J. Meteor. Res., 34, 427-459, https://doi.org/ 10.1007/s13351-020-0006-x.

Maddox, R. A., 1983: Large-scale meteorological conditions associated with midlatitude, mesoscale convective complexes. Mon. Wea. Rev., 111, 1475-1493, https://doi.org/ 10.1175/1520-0493(1983)111<1475:LSMCAW>2.0.CO;2.

Moore, J. T., F. H. Glass, C. E. Graves, S. M. Rochette, and M. J. Singer, 2003: The environment of warm-season elevated thunderstorms associated with heavy rainfall over the central United States. Wea. Forecasting, 18, 861-878, https://doi.org/10.1175/1520-0434(2003)018<0861:TEOWET $>$ 2.0.CO;2.

Mulholland, J. P., S. W. Nesbitt, and R. J. Trapp, 2019: A case study of terrain influences on upscale convective growth of a supercell. Mon. Wea. Rev., 147, 4305-4324, https://doi.org/ 10.1175/MWR-D-19-0099.1.

Parsons, D., K. Haghi, K. Halbert, B. Elmer, and J. Wang, 2019: The potential role of atmospheric bores and gravity waves in the initiation and maintenance of nocturnal convection over the Southern Great Plains. J. Atmos. Sci., 76, 43-68, https:// doi.org/10.1175/JAS-D-17-0172.1.

Pitchford, K. L., and J. London, 1962: The low-level jet as related to nocturnal thunderstorms over Midwest United States. J. Appl. Meteor., 1, 43-47, https://doi.org/10.1175/ 1520-0450(1962)001<0043:TLLJAR > 2.0.CO;2.

Rotunno, R., J. B. Klemp, and M. L. Weisman, 1988: A theory for strong, long-lived squall lines. J. Atmos. Sci., 45, 463-485, https://doi.org/10.1175/1520-0469(1988)045<0463:ATFSLL > 2.0.CO;2.

Schumacher, R. S., and R. H. Johnson, 2005: Organization and environmental properties of extreme-rain-producing mesoscale convective systems. Mon. Wea. Rev., 133, 961-976, https://doi.org/10.1175/MWR2899.1. 
Shapiro, A., E. Fedorovich, and S. Rahimi, 2016: A unified theory for the Great Plains nocturnal low-level jet. J. Atmos. Sci., 73, 3037-3057, https://doi.org/10.1175/JAS-D-15-0307.1.

,-- , and J. G. Gebauer, 2018: Mesoscale ascent in nocturnal low-level jets. J. Atmos. Sci., 75, 1403-1427, https://doi.org/ 10.1175/JAS-D-17-0279.1.

Shen, Y., Y. Du, and G. Chen, 2020: Ensemble sensitivity analysis of heavy rainfall associated with three MCSs coexisting over southern China. J. Geophys. Res. Atmos., 125, e2019JD031266, https://doi.org/10.1029/2019JD031266.

Skamarock, W. C., and Coauthors, 2008: A description of the Advanced Research WRF version 3. NCAR Tech. Note NCAR/TN475+STR, 113 pp., https://doi.org/10.5065/D68S4MVH.

Smith, E. N., J. G. Gebauer, P. M. Klein, E. Fedorovich, and J. A. Gibbs, 2019: The Great Plains low-level jet during PECAN: Observed and simulated characteristics. Mon. Wea. Rev., 147, 1845-1869, https://doi.org/10.1175/MWR-D-18-0293.1.

Sun, J., Y. Zhang, and R. Liu, 2019: A review of research on warmsector heavy rainfall in China. Adv. Atmos. Sci., 36, 1299-1307, https://doi.org/10.1007/s00376-019-9021-1.

Thompson, G., P. R. Field, R. M. Rasmussen, and W. D. Hall, 2008: Explicit forecasts of winter precipitation using an improved bulk microphysics scheme. Part II: Implementation of a new snow parameterization. Mon. Wea. Rev., 136, 5095-5115, https://doi.org/10.1175/2008MWR2387.1.

Toth, Z., and E. Kalnay, 1993: Ensemble forecasting at NMC: The generation of perturbations. Bull. Amer. Meteor. Soc., 74, 2317-2330, https://doi.org/10.1175/1520-0477(1993)074<2317: EFANTG $>2.0 . \mathrm{CO} ; 2$.

Trier, S. B., 2003: Convective storms: Convective intiation. Encyclopedia of Atmospheric Sciences, J. Holton and J. Curry, Eds., Oxford University Press, 560-570.

_ preceding the development of a nocturnal mesoscale convective complex. Mon. Wea. Rev., 121, 1078-1098, https://doi.org/10.1175/ 1520-0493(1993)121<1078:EOECPT>2.0.CO;2.

- C. A. Davis, D. A. Ahijevych, M. L. Weisman, and G. H. Bryan, 2006: Mechanisms supporting long-lived episodes of propagating nocturnal convection within a 7-day WRF model simulation. J. Atmos. Sci., 63, 2437-2461, https://doi.org/10.1175/JAS3768.1.

—, J. W. Wilson, D. A. Ahijevych, and R. A. Sobash, 2017: Mesoscale vertical motions near nocturnal convection initiation in PECAN. Mon. Wea. Rev., 145, 2919-2941, https:// doi.org/10.1175/MWR-D-17-0005.1.

_ S. D. Kehler, and J. Hanesiak, 2020: Observations and simulation of elevated nocturnal convection initiation on 24 June 2015 during PECAN. Mon. Wea. Rev., 148, 613-635, https:// doi.org/10.1175/MWR-D-19-0218.1.
Wang, H., Y. Luo, and B. Jou, 2014: Initiation, maintenance, and properties of convection in an extreme rainfall event during SCMREX: Observational analysis. J. Geophys. Res. Atmos., 119, 13 206-13 232, https://doi.org/10.1002/2014JD022339.

Weckwerth, T. M., and D. B. Parsons, 2006: A review of convection initiation and motivation for IHOP_2002. Mon. Wea. Rev., 134, 5-22, https://doi.org/10.1175/MWR3067.1.

, J. Hanesiak, J. W. Wilson, S. B. Trier, S. K. Degelia, W. A. Gallus, R. D. Roberts, and X. Wang, 2019: Nocturnal convection initiation during PECAN 2015. Bull. Amer. Meteor. Soc., 100, 2223-2239, https://doi.org/10.1175/BAMS-D-18-0299.1.

Wei, M., Z. Toth, R. Wobus, and Y. Zhu, 2008: Initial perturbations based on the ensemble transform (ET) technique in the NCEP global operational forecast system. Tellus, 60A, 62-79, https:// doi.org/10.1111/j.1600-0870.2007.00273.x.

Whiteman, C. D., X. Bian, and S. Zhong, 1997: Low-level jet climatology from enhanced rawinsonde observations at a site in the southern Great Plains. J. Appl. Meteor., 36, 1363-1376, https:// doi.org/10.1175/1520-0450(1997)036<1363:LLJCFE >2.0.CO;2.

Wilson, J. W., and R. D. Roberts, 2006: Summary of convective storm initiation and evolution during IHOP: Observational and modeling perspective. Mon. Wea. Rev., 134, 23-47, https:// doi.org/10.1175/MWR3069.1.

Wu, N., X. Ding, Z. Wen, G. Chen, Z. Meng, L. Lin, and J. Min, 2020a: Contrasting frontal and warm-sector heavy rainfalls over south China during the early-summer rainy season. Atmos. Res., 235, 104693, https://doi.org/10.1016/j.atmosres.2019.104693.

_ - X. Zhuang, J. Min, and Z. Meng, 2020b: Practical and intrinsic predictability of a warm-sector extreme torrential rainfall event in the south China monsoon region. J. Geophys. Res. Atmos., 125, e2019JD031313, https://doi.org/10.1029/2019JD031313.

Xue, M., X. Luo, K. Zhu, Z. Sun, and J. Fei, 2018: The controlling role of boundary layer inertial oscillations in Meiyu frontal precipitation and its diurnal cycles over China. J. Geophys. Res. Atmos., 123, 5090-5115, https://doi.org/ 10.1029/2018JD028368.

Zeng, W., G. Chen, Y. Du, and Z. Wen, 2019: Diurnal variations of low-level winds and rainfall response to large-scale circulations during a heavy rainfall event. Mon. Wea. Rev., 147, 3981-4004, https://doi.org/10.1175/MWR-D-19-0131.1.

Zhang, M., and Z. Meng, 2019: Warm-sector heavy rainfall in southern China and its WRF simulation evaluation: A lowlevel-jet perspective. Mon. Wea. Rev., 147, 4461-4480, https:// doi.org/10.1175/MWR-D-19-0110.1.

, - _ Y Y. Huang, and D. Wang, 2019: The mechanism and predictability of an elevated convection initiation event in a weaklifting environment in central eastern China. Mon. Wea. Rev., 147, 1823-1841, https://doi.org/10.1175/MWR-D-18-0400.1. 